\title{
Latent, Immunosuppressive Nature of Poly(lactic-co-glycolic acid) Microparticles
}

\author{
Riley P. Allen ${ }^{\dagger}$, Amir Bolandparvaz ${ }^{\dagger}$, Jeffrey A. $\mathbf{M a}^{\dagger}$, Vishal A. Manickam ${ }^{\dagger}$, and Jamal S. \\ Lewis ${ }^{*}, \dagger$ \\ †Department of Biomedical Engineering, University of California Davis, 1 Shields Avenue, Davis, \\ California 95616, United States
}

\begin{abstract}
Use of biomaterials to spatiotemporally control the activation of immune cells is at the forefront of biomedical engineering research. As more biomaterial strategies are employed for immunomodulation, understanding the immunogenicity of biodegradable materials and their byproducts is paramount in tailoring systems for immune activation or suppression. Poly(D,Llactic-co-glycolic acid) (PLGA), one of the most commonly studied polymers in tissue engineering and drug delivery, has been previously described on one hand as an immune adjuvant, and on the other as a nonactivating material. In this study, the effect of PLGA microparticles (MPs) on the maturation status of murine bone marrow-derived dendritic cells (DCs), the primary initiators of adaptive immunity, was investigated to decipher the immunomodulatory properties of this biomaterial. Treatment of bone marrow-derived DCs from C57BL/6 mice with PLGA MPs led to a time dependent decrease in the maturation level of these cells, as quantified by decreased expression of the positive stimulatory molecules MHCII, CD80, and CD86 as well as the ability to resist maturation following challenge with lipopolysaccharide (LPS). Moreover, this immunosuppression was dependent on the molecular weight of the PLGA used to fabricate the MPs, as higher molecular weight polymers required longer incubation to produce comparable dampening of maturation molecules. These phenomena were correlated to an increase in lactic acid both intracellularly and extracellularly during DC/PLGA MP coculture, which is postulated to be the primary agent behind the observed immune inhibition. This hypothesis is supported by our results demonstrating that resistance to LPS stimulation may be due to the ability of PLGA MP-
\end{abstract}

*Corresponding Author: Tel.: (530)752-4753; jamlewis@ucdavis.edu.

ORCID

Jamal S. Lewis: 0000-0002-9811-8538

Author Contributions

R.P.A. contributed to the design and execution of experiments, analysis of data, and compilation of the manuscript. A.B, J.M., and V.A.M. contributed to the execution of experiments and analysis of data. J.S.L. contributed to the design of experiments, analysis of data, and manuscript compilation. J.S.L. had primary responsibility for the content of the manuscript.

Notes

The authors declare no competing financial interest.

\section{ASSOCIATED CONTENT}

Supporting Information

The Supporting Information is available free of charge on the ACS Publications website at DOI: 10.1021/acsbiomater-ials.7b00831. $\mathrm{pH}$ measurements of cell culture media during both PLGA MP and sLA treatments; cytotoxicity of PLGA MPs; apoptotic activity of cells treated with sLA and PLGA MPs with corresponding flow cytometry dot plots; representative flow plots from maturation and maturation resistance studies; representative flow plots from mixed lymphocyte reactions showing CFSE proliferation; brightfield images of DCs in culture with PLGA MPs (Figures S1-S9) (PDF) 
derived lactic acid to inhibit the phosphorylation of TAK1 and therefore prevent NF- $x$ B activation. This work is significant as it begins to elucidate how PLGA, a prominent biomaterial with broad applications ranging from tissue engineering to pharmaceutics, could modulate the local immune environment and offers insight on engineering PLGA to exploit its evolving immunogenicity.

\section{Graphical Abstract}

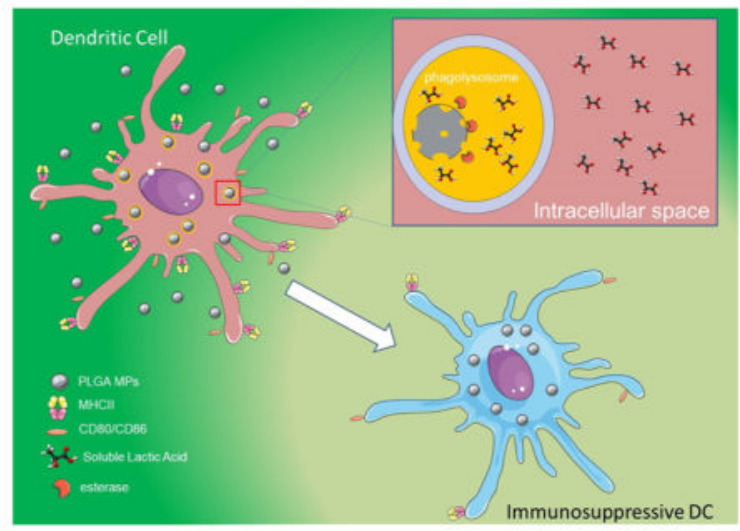

\section{Keywords}

poly(lactic-co-glycolic) acid; dendritic cells; immunogenicity; microparticles; lactic acid

\section{INTRODUCTION}

Dendritic cells (DCs) are currently at the forefront of cell-based therapeutic research for their ability to orchestrate the adaptive immune response. Dendritic cells are considered to be "professional" antigen-presenting cells (APCs). In this capacity, they reside in peripheral tissues (in an immature state) and survey the tissue environment through a number of mechanisms, including macropinocytosis and phagocytosis. ${ }^{1}$ Upon activation, often due to immunostimulators such as Toll-like receptor (TLR) agonists or inflammatory cytokines (e.g., Interleukin-12 [IL-12]), DCs obtain a mature phenotype. This characteristic activation is typically denoted by increased expression of costimulatory molecules (e.g., CD80, CD86), the major histocompatibility complex class II (MHCII), and increased production of inflammatory cytokines, particularly IL-12.,3 Following maturation, DCs also upregulate lymph node-homing receptors. For example, chemokine receptor 7 (CCR7), which promotes DC migration to draining lymphoid organs upon ligation to its cognitive chemokine.,

Conversely, maintenance of the immature DC (iDC) phenotype, characterized by low expression of MHCII and costimulatory molecules, as well as production of antiinflammatory cytokines (e.g., IL-10) can promote the induction and expansion of regulatory $T$ cells $\left(T_{\text {regs }}\right.$ ), and promote antigen-specific tolerance. ${ }^{6,7}$ In the same vein, tolerogenic DCs (tDCs) can promote central and peripheral tolerance via a number of mechanisms, including $\mathrm{T}$ cell anergy, $\mathrm{T}_{\text {reg }}$ generation, and effector $\mathrm{T}$ cell deletion. ${ }^{6}$ Tolerogenic DCs are characterized by low expression of MHCII, CD80, CD86, secretion of anti-inflammatory cytokines (e.g., IL-10), and increased expression of tyrosine-based inhibitory motifs (ITIMs) 
containing surface receptors and ligands (e.g., ILT-3). The tolerogenic capacity of DCs has spurred investigation into their potential application as live "anti-vaccines" against autoimmune conditions. 8,9

Current efforts in this realm have employed autologous human monocyte-derived tDCs, which can be generated under clinical conditions in great numbers and with appropriate immunoinhibitory properties. ${ }^{10,11}$ However, this strategy has major challenges that threaten to limit its widespread application, including the inconsistency of DC maturation state, limited DC viability and trafficking to immune relevant areas, ex vivo cell stability, posttransfer survivability, and tremendous manufacturing costs. ${ }^{6}$ Additionally, it has been reported that exogenous loading of peptides results in $\mathrm{MHC} /$ peptide complexes with short half-lives, which limits the therapeutic efficacy of DCs following in vivo infusion. ${ }^{12}$

An appealing alternative to exogenous conditioning is the administration of biomaterialbased particulate systems capable of conditioning DCs in vivo toward any modality. ${ }^{8,13,14}$ Programming of dendritic cells (DCs), the master controller of adaptive immunity, through engineered biomaterials is a potentially transformative strategy for effective vaccination, tissue engineering, and immunotherapy. Biomaterial particulates have been engineered to mimic nano- to micrometer-sized pathogens such as bacteria and viruses, which DCs have evolved to intercept and eliminate. ${ }^{15}$ Further, a number of functionalities have been incorporated into biomaterial particulates to control immune cell interactions and desired responses. Qualities that have been engineered into material particles include size and shape for efficient intracellular or extracellular delivery, encapsulation ability for delivery of antigen and immunomodulatory molecules, surface functionalization to trigger specific cellular and humoral immune cascades, and tunable release of chemoattractant factors to recruit DCs to the site of injection..$^{8,13,16-19}$ The most investigated biomaterial for particulate-based immune modulation is poly(D,L-lactic-co-glycolic-acid) (PLGA). ${ }^{20,21}$ Poly(D,L-lactic-co-glycolic-acid) has been researched for both immunosuppressive and immunostimulatory applications. For instance, Lewis et al. previously reported that a dualsized PLGA-based microparticle (MP) system loaded with tolerogenic factors prevented hyperglycemia in the nonobese autoimmune diabetic mouse model. ${ }^{8}$ This same group later showed that this system could be effectively translated to other disease models simply by switching the disease-relevant antigen. ${ }^{22}$ On the other hand, PLGA nanoparticles (NPs) functionalized with DC-targeting molecules have been used to increase melanoma specific antigen (MART-1) presentation to $\mathrm{CD}^{+} \mathrm{T}$ cells for improved cancer immunotherapy. ${ }^{23}$ These reports suggest that PLGA-based particulate systems may be therapeutically effective at both ends of the spectrum of immunological conditions.

Unsurprisingly, there have been contrasting reports on the immunogenicity of PLGA. 8,21,24-26 Some reports, performed at shorter time periods, show increased IL- $\beta$ production through activation of the NALP3 inflammasome. Moreover, these findings suggest that PLGA has intrinsic immunogenic properties which may be counterproductive to the purpose of tolerance induction. ${ }^{25-29}$ On the other hand, Waeckerle-Men et al. and Lewis et al. reported that PLGA MPs have no apparent immunostimulatory properties and may even be immunosuppressive. ${ }^{21,30}$ Overall, efforts to decipher the immunogenicity (or tolerogenicity) of PLGA have been inadequate, often executed in an acute time frame and only considerate 
of the contact dependent nature of DC-PLGA interactions. As a result, there is a significant knowledge gap on the effects of this important biomaterial on immune cells.

Poly(D,L-lactic-co-glycolic-acid) polymers are polyesters made of lactic and glycolic acids at molar ratios typically ranging between 50:50 and 100\% lactic acid. ${ }^{31,32}$ Copolymer composition and molecular weight are both influential on the hydrophobicity and degradation characteristics of PLGA as well as the release kinetics of entrapped materials. ${ }^{31}$ Upon in vivo administration, PLGA MPs $(\sim 1-10 \mu \mathrm{m})$ can be taken up and degraded within specialized vacuoles of phagocytic cells. ${ }^{33}$ The ester bond linking the two acids is hydrolyzed inside the phagolysosome, liberating the monomeric units of lactic acid and glycolic acid. ${ }^{31}$ Moreover, lactic acid, a byproduct of glycolysis which is often found at high concentrations in tumor microenvironments, has been shown to increase the production of the anti-inflammatory cytokine IL-10, suppress the expression of costimulatory molecules (e.g., CD86) and decrease the antigen-presenting ability of DCs. ${ }^{34-36}$ Therefore, we hypothesize that the gradual breakdown of PLGA MPs within the phagolysosome of DCs into lactic acid (and glycolic acid) has time dependent, immunosuppressive effects on DCs. To maximize the therapeutic efficacy of PLGA-based immunother-apeutics, the effect of PLGA on DCs (and other immune cells) must be fully understood. This study is critical as it sheds light on the interaction between DCs and degradable polymeric particles and examines the evolution of immunogenicity of these biomaterials as degradation liberates monomers with potentially different immunomodulatory properties from the polymer. Knowledge garnered from this study could support the rational design of polymers that serve not only as delivery vehicles but also as agents that help to orchestrate immune responses.

\section{MATERIALS AND METHODS}

\subsection{Preparation of Unloaded Microparticles and Fluorescently Loaded MPs}

Several different PLGA compositions with differing molecular weights were purchased from commercial sources to examine the immunogenicity of PLGA MPs on DCs. For the initial studies, two PLGA ( $\left.M_{\mathrm{w}} \sim 10 \mathrm{kDa}\right)$ acid-terminated polymers (Corbion, Netherlands) with differing ratios of lactic to glycolic acid 50:50 (PURASORB PDLG 5002A), 75:25 (PURASORB PDLG 7502A), and an acid-terminated poly(D,L-lactic acid) (PLA; $M_{\mathrm{w}} \sim 10$ $\mathrm{kDa}$ ) (PURASORB PDL 02A) were used. Henceforth, these formulations are referred to as PLG50, PLG75, and PL100, respectively. We also utilized 50:50 PLGA polymers with higher molecular weights, including an acid-terminated PLGA $\left(M_{\mathrm{w}} \sim 22 \mathrm{kDa}\right.$; PURASORB PDLG 5004A) and an ester-terminated PLGA ( $M_{\mathrm{w}} \sim 90 \mathrm{kDa}$; PURASORB PDLG 5010). These compositions are referred to as 5004A and 5010, respectively.

To make phagocytostable MPs, the PLGA and PLA polymers were dissolved in methylene chloride (Fisher Scientific, New Jersey, United States) at $5 \% \mathrm{w} / \mathrm{v}$ ratio. ${ }^{30}$ For fluorescently labeled MPs, either rhodamine 6G (Acros Organics, Geel, Belgium) or fluorescein (Acros Organics) was codissolved with PLG50, PLG75, or PL100 in methylene chloride at a ratio of $0.6 \mathrm{mg}$ dye $/ 100 \mathrm{mg}$ polymer. This solution was added to $2 \mathrm{~mL}$ of $5 \%$ poly(vinyl alcohol) (PVA; Fisher Scientific; $87 \%$ hydrolyzed, $M_{\mathrm{W}} 100000 \mathrm{~g} / \mathrm{mol}$ ) solution in $\mathrm{diH}_{2} \mathrm{O}$ purchased from Fisher Scientific and homogenized at $35000 \mathrm{rpm}$ for $180 \mathrm{~s}$ using a Tissuemiser homogenizer (OMNI, Kennesaw, GA) to form a primary emulsion. This solution was added 
to $30 \mathrm{~mL}$ of $1 \%$ PVA solution. The particles thus formed were agitated using a magnetic stirrer (Fisher Scientific) for $24 \mathrm{~h}$ to evaporate residual methylene chloride. The remaining solution was centrifuged at $10000 \mathrm{~g}$ for $15 \mathrm{~min}$ to collect MPs. The pelleted MPs were subsequently washed three times with $\mathrm{diH}_{2} \mathrm{O}$. The water was aspirated from the centrifuged MPs on the final wash, and the remaining pellet was lyophilized overnight. The MPs were stored at $-20{ }^{\circ} \mathrm{C}$ until use.

\subsection{Characterization of MPs}

Microparticles were assessed for size and $\zeta$-potential in $\mathrm{diH}_{2} \mathrm{O}$ using the Malvern ZetaSizer Nano ZS (Malvern Instruments, UK). Additionally, we determined the endotoxin content of MPs using the Chromo-Limulus Amebocyte Lysate (ChromoLAL) kinetic endotoxin test (Cape Cod, Falmouth, MA). Scanning electron microscopy images were captured using Philips/FEI XL30 SFEG Scanning Electron Microscope (SEM) for morphological and size assessment. Samples were prepared by sonicating a $10 \mathrm{mg} / \mathrm{mL}$ solution of PLGA MPs in water and drying on carbon tape overnight $(16 \mathrm{~h})$. These samples were then sputtered with gold (5-10 nm-thick layer) using $45 \mathrm{~A}$ current for 1 min (Perkins-Elmer) and imaged at magnifications ranging from $30 \times$ to $60000 \times$.

\subsection{Generation of Bone Marrow-Derived DCs}

Dendritic cells were obtained from 8-12 weeks old, male and female, C57BL6/j mice in accordance with guidelines approved by the University of California, Davis, Animal Care and Use Committee (IACUC) using a modified 10 day protocol. ${ }^{37}$ For DC culture, mice were euthanized by $\mathrm{CO}_{2}$ asphyxiation followed by cervical dislocation, and tibias and femurs were harvested for isolating bone marrow cells. The bone marrow cells were obtained by flushing the shaft of the long bones with a $25 \mathrm{~g}$ needle using RPMI medium w/L-glutamine and $25 \mathrm{mM}$ HEPES (Mediatech, Manassas, VA) containing $1 \%$ fetal bovine serum (Mediatech) and 1\% penicillin/streptomycin (Hyclone) and mixed to make a homogeneous suspension. The suspension was then strained using $70 \mathrm{~mm}$ cell strainers (Becton Dickinson, NJ, United States), and cells were collected at $1800 \mathrm{rpm}$ for $5 \mathrm{~min}$. The red blood cells (RBCs) were lysed with ACK lysis buffer (Lonza, Walkersville, MD) followed by centrifugation at $1800 \mathrm{rpm}$ for $5 \mathrm{~min}$ to recover leukocytes. Leukocytes were then resuspended in DMEM/F-12 1:1 with L-glutamine (Cellgro, Herndon, VA), 10\% fetal bovine serum, $1 \%$ sodium pyruvate (Lonza, Walkersville, MD), $1 \%$ nonessential amino acids (Lonza, Walkersville, MD), 1\% penicillin/streptomycin (Hyclone) and $20 \mathrm{ng} / \mathrm{mL}$ GMCSF (R\&D Systems, MN, United States) (DC media) and plated on tissue culture flasks for 2 days to remove adherent cells. At two days, the nonadherent cells were transferred to low attachment plates and cultured in fresh DC media for expansion of DC precursor cells. At six days, cells were transferred to tissue culture plates to allow for DC adhesion and proliferation. At ten days, the cells were used for the studies described below.

\subsection{Particle Uptake and Internalization}

Dendritic cells were incubated in a 1,1-dioctadecyl-3,3,3,3-tetramethylindodicarbocyanine (DiD) solution (AAT Bioquest, Sunnyvale, CA)) $(1 \mu \mathrm{M})$ for $1 \mathrm{~h}$ to track live cells. Following a washing step to remove free $\mathrm{DiD}, \mathrm{DCs}\left(0.5 \times 10^{6}\right.$ cells $)$ were cocultured with rhodamine-6G-loaded PLG50, PLG75, and PL100 MPs for $6 \mathrm{~h}$ while being gently agitated 
at $50 \mathrm{rpm}$ at $37{ }^{\circ} \mathrm{C}$ in a $2 \mathrm{mM}$ dextrose solution. Microparticles were dispersed into the cell culture media at a 10:1 ratio $(\sim 0.4 \mathrm{mg} / \mathrm{mL})$, a concentration widely used in biomedical applications. ${ }^{38}$ Flow cytometric analysis (Attune NxT, Life Technologies) was then performed at the specified time points to determine the percent of cells positive for both the rhodamine 6G and DiD channels as a measure of phagocytic activity. Controls, including cell-only, unstained cells, and MP-only suspensions, were also assessed by flow cytometry.

Internalization of MPs was confirmed using fluorescent confocal microscopy. At day 6 of culture, cells were plated on a $35 \mathrm{~mm}$ glass bottom microwell dish (MatTek Corporation, Ashland, MA) pretreated with $1 \%$ w/v bovine collagen-II (Sigma-Aldrich, St. Louis, MO) in $0.25 \%$ acetic acid (Fisher Scientific) overnight at $4{ }^{\circ} \mathrm{C}$. Cells were incubated with fluorescein-labeled particles at a ratio of 10:1 MP to cell for $24 \mathrm{~h}$. Following incubation, cells were washed thoroughly with cold PBS and fixed with $4 \%$ methanol free paraformaldehyde (Thermo Fisher Scientific, Waltham, MA). Following flxation, cells were permeabilized with a $1 \%$ Tween-80 solution in $0.25 \mathrm{M}$ sucrose (Sigma-Aldrich) for $45 \mathrm{~min}$. After the permeabilization step, cells were stained with a fluorescent Texas-RED X phalloidin (Thermo Fisher Scientific) to visualize actin cytoskeleton elements.

\subsection{Dendritic Cell Phenotype-Maturation Markers}

For these studies, either PLG50 MPs, PLG75 MPs, PL100 MPs, 5004A MPs, 5010 MPs, sodium L-lactate (sLA; Sigma-Aldrich [L7022]), lipopolysaccharide (LPS; $1.5 \mu \mathrm{g} / \mathrm{mL}$, Sigma-Aldrich), or polyinosinic-polycytidilic acid (poly[I:C], $25 \mu \mathrm{g} / \mathrm{mL}$, Sigma-Aldrich) were added to DC cultures at $37{ }^{\circ} \mathrm{C}$ and $5 \% \mathrm{CO}_{2}$ for a period of $6,24,48,72,96$, and $120 \mathrm{~h}$ prior to analysis. Microparticles were cocultured at a ratio of 10:1 MPs per cell $(\sim 0.4 \mathrm{mg} /$ $\mathrm{mL}$ ). In these experiments, half the media was discarded and replaced with fresh media every two days, the plates were tilted and the media was pipetted slowly to avoid disturbing any settled particulate matter. The $\mathrm{pH}$ of cell culture supernatants was measured using the Accumet AP110 electronic pH reader. pH measurements were taken in triplicate. Dendritic cell immunophenotype was quantified by measuring cell surface marker expression by flow cytometry. Following MP incubation, DCs were lifted by incubating with a $2 \mathrm{mM} \mathrm{Na} 2 \mathrm{EDTA}$ (Fisher Scientific) in PBS solution at $37^{\circ} \mathrm{C}$ for $10 \mathrm{~min}$. Dendritic cells were then washed with $1 \%$ fetal bovine serum in PBS and incubated with antibodies against CD16/CD32 (Fc $\gamma$ III/II Receptor) (clone 2.4G2, IgG2b, k); (BD Pharmingen, CA, United States) for $15 \mathrm{~min}$ at $4{ }^{\circ} \mathrm{C}$ to block Fc $\gamma$ receptors on DCs. Cells were washed and then stained with antibodies against CD80 (clone 16-10A1, IgG2, k), CD86 (clone GL1, IgG2a, k), I-A/I-E (clone M5/114.15.2, IgG2b, k), CD11c (clone HL3, IgG1, 12), and CD197 (clone 4B12, IgG2a, k) (BD Pharmingen) for $30 \mathrm{~min}$ at $4{ }^{\circ} \mathrm{C}$. Data acquisition was performed using (Attune NxT, Life Tech) flow cytometry, and the geometric fluorescent intensities and percent of positively stained cells were determined. More than 10000 events were acquired for each sample, and data analysis was performed using FCS Express version 4 (De Novo Software, Los Angeles, CA). 


\subsection{Cytotoxicity}

Cytotoxicity of the PLGA MPs and sLA at varying concentrations was tested using the LDH Cytotoxicity Assay Kit (Thermo Fischer Scientific). The standard protocol assays reported here were performed according to the manufacturer's instructions.

\subsection{Cell Apoptosis after Coculture PLGA MP and sLA}

Cell viability was also assessed using a combination of Annexin- $\mathrm{V}$ and propidium iodide (PI) staining. DCs were cocultured for $120 \mathrm{~h}$ with either PLGA MPs or SLA, as described in Section 2.5. Subsequently, DCs $\left(5 \times 10^{5} /\right.$ well $)$ were lifted by incubating in a $2 \mathrm{mM}$ $\mathrm{Na}_{2} \mathrm{EDTA} / \mathrm{PBS}$ solution at $37^{\circ} \mathrm{C}$ for $10 \mathrm{~min}$, followed by gentle scraping. Dendritic cells were then washed with $1 \%$ fetal bovine serum and suspended in binding buffer $(0.01 \mathrm{M}$ HEPES [pH 7.4], $0.14 \mathrm{M} \mathrm{NaCl}, 2.5 \mathrm{mM} \mathrm{CaCl})$. Cells were then incubated with $5 \mu \mathrm{L} \mathrm{PE-}$ CF594 Annexin-V (BD Bioscience) for $15 \mathrm{~min}$ at room temperature. Cells were then stained with PI ready flow reagent (Thermo Fisher Scientific). Two drops $(\sim 80 \mu \mathrm{L})$ of PI were added to the cell suspension, and the solution was incubated for $15 \mathrm{~min}$ at room temperature prior to analysis via flow cytometry.

\subsection{Secretion-Cytokine Analysis}

Cell culture supernatants were collected after respective MP and control treatment incubations, centrifuged to remove any cell debris and stored at $-20{ }^{\circ} \mathrm{C}$ until analysis. The secretion of IL-12p70 was analyzed using sandwich enzyme-linked immunosorbent assay (ELISA) kit (Becton Dickinson, NJ, United States) according to manufacturer's directions.

\subsection{CD4+ T Cell Isolation and CFSE Staining}

Mouse $\mathrm{CD}^{+} \mathrm{T}$ cells were purified from BALB/cByJ splenocyte suspensions by negative selection using Miltenyi Biotec $\mathrm{CD} 4^{+} \mathrm{T}$ cell isolation kit II, following the manufacturer's instructions. The relative purity as determined by flow cytometry was greater than $90 \%$. $\mathrm{T}$ cells were subsequently stained with carboxyfluorescein succinimidyl ester (CFSE; CellTrace Cell Proliferation Kit, Thermo Fisher Scientific) according to the manufacturer's specifications.

\subsection{Mixed Lymphocyte Reactions}

For the mixed lymphocyte reaction studies, C57BL/6J DCs $\left(2.5 \times 10^{4}\right.$ cells/well $)$ were plated onto a 96-well tissue culture plate. Dendritic cells were cocultured with PLG50, PLG75, or PL100 MPs for $48 \mathrm{~h}$. Additionally, DCs were cocultured with PLG50, PLG75, or PL100 MPs for $48 \mathrm{~h}$, washed, and challenged with LPS at $1.5 \mu \mathrm{g} / \mathrm{mL}$ for $24 \mathrm{~h}$. After DCs were thoroughly washed with PBS, CFSE-stained BALB/cByJ CD4+ T cells $\left(1.25 \times 10^{5}\right.$ cells/well) were added and incubated at $37{ }^{\circ} \mathrm{C}$ for $72 \mathrm{~h}$. After $72 \mathrm{~h}$, nonadherent T cells were removed and stained with anti-CD4 (clone RM4-5, IgG2a, $x$ ) (BD Pharmingen). Flow cytometry was then used to quantify $\mathrm{T}$ cell proliferation via CFSE dilution. More than 10 000 events were acquired for each sample, and data analysis was performed using FCS Express version 4 Proliferation analysis (De Novo Software, Los Angeles, CA). Phorbol 12myristate 13-acetate- (PMA; [20 ng/mL]) and ionomycin- (IONO; $[1 \mu \mathrm{g} / \mathrm{mL}]$ ) stimulated cells were used as proliferation controls. 


\subsection{Lactic Acid Assay}

A glycolysis cell-based assay kit for lactic acid measurements was purchased from Cayman Chemical (Ann Arbor, MI). Lactic acid assays were conducted according to manufacturer's specifications using DC cultures seeded at $5 \times 10^{5}$ cells/well.

\subsection{Western Blot Assay for NF- $x B$}

Western blots were performed to assess the expression level of NF- $\kappa$ B in DCs. Dendritic cells were cultured as previously described (Section 2.3 ). On day 6 , cells were seeded at a density of $1 \times 10^{6}$ cells/well in a 6-well tissue culture-treated plate. Cells were then cocultured with MPs (PLG50, PLG75, or PL100) at a ratio of 10:1 MPs per cell for the designated time period and subsequently stimulated with LPS $(1.5 \mu \mathrm{g} / \mathrm{mL})$ for $24 \mathrm{~h}$. Additionally, DCs were cultured in DC media supplemented with $100 \mathrm{mM}$ sLA for the designated time period and then stimulated with LPS for $24 \mathrm{~h}$ in fresh DC media with no sLA. Control groups in this experiment included untreated DCs and DCs treated with LPS for the same time period as MP coculture. Following coculture, cells were lifted and lysed in lysis buffer (Pierce) supplemented with $0.5 \% \mathrm{w} / \mathrm{v}$ sodium deoxycholate, $0.1 \% \mathrm{w} / \mathrm{v}$ sodium dodecyl sulfate (SDS), and protease inhibitors for $30 \mathrm{~min}$ at $4{ }^{\circ} \mathrm{C}$. Following lysis, the solution was spun at $16000 \mathrm{~g}$ for $20 \mathrm{~min}$ at $4{ }^{\circ} \mathrm{C}$. Protein concentration in each lysate was determined using the Bradford assay. ${ }^{39}$ Equal amounts of each protein were loaded for $7 \%$ SDS-polyacrylamide gel electrophoresis (7\% SDS-PAGE) and transferred to a polyvinylidene difluoride PVDF membrane. The membrane was blocked in 5\% milk for $1 \mathrm{~h}$ and incubated with primary antibodies [human/mouse RelA/NF $\kappa$ B p65 (R\&D Systems)] and $\beta$-actin (clone AC-15, Thermo Fisher Scientific) overnight. Protein was visualized utilizing an alkaline phosphatase-conjugated secondary antibody and Immun-Star Alkaline Phosphatase Chemiluminescent Substrate (BioRad, Hercules, California). For each result, at least three independent sets of Western blot experiments were performed. Immunoblots were analyzed using the Gel Doc XR+ Gel Documentation System and ImageJ software.

\subsection{NF- $\nprec$ B Pathway Inhibition Studies}

Phosphorylation of key signaling molecules involved in the activation of NF- $x \mathrm{~B}$ via the TLR-4/MyD88 pathway was assessed after treatment with PLGA MPs. Dendritic cells were cultured as previously described (Section 2.3). On day 6, cells were seeded at a density of 5 $\times 10^{6}$ cells/well in 12-well tissue culture-treated plates. Cells were then cocultured with MPs (PLG50, PLG75, or PL100) at a ratio of 10:1 MP to cell for the designated time period and subsequently stimulated with LPS $(1.5 \mu \mathrm{g} / \mathrm{mL})$ for $24 \mathrm{~h}$. Additionally, DCs were cultured in DC media supplemented with $100 \mathrm{mM}$ sLA for the designated time period and then stimulated with LPS for $24 \mathrm{~h}$ in fresh DC media with no sLA. Second, DCs were incubated with LPS for $24 \mathrm{~h}$ and then pulsed with small molecule inhibitors of TAK1 and IKK $\beta$, (5Z)-7-oxozeaenol (5 $\mu \mathrm{M}$ in DMSO) and ML120B (10 $\mu \mathrm{M}$ in DMSO) for $2 \mathrm{~h} .{ }^{40,41}$ Following designated incubation periods, DCs were lifted by incubating with a $2 \mathrm{mM}$ $\mathrm{Na}_{2}$ EDTA (Fisher Scientific) in PBS solution at $37^{\circ} \mathrm{C}$ for $10 \mathrm{~min}$. Dendritic cells were then washed with $1 \%$ fetal bovine serum in PBS and incubated with antibodies against CD16/ CD32 (Fc $\gamma$ III/II Receptor) (clone 2.4G2, IgG2b, k) (BD Pharmingen, CA, United States) for $15 \mathrm{~min}$ at $4{ }^{\circ} \mathrm{C}$ to block $\mathrm{Fc} \gamma$ receptors on DCs. Cells were then stained for the DC 
surface marker CD11c (clone HL3, IgG1, 12), for 30 min at $4{ }^{\circ} \mathrm{C}$. Subsequently, cells were fixed using $4 \%$ formaldehyde for $15 \mathrm{~min}$ at room temperature. Following fixation cells were permeabilized using ice cold methanol for $30 \mathrm{~min}$ on ice. Cells were then washed in PBS and incubated with fluorescently conjugated anti-phoshoTAK1 (Thr184) (Aviva Biosystems, San Diego, CA) and anti-phosphoIKK $\beta / a$ (Ser 176/180) (Cell Signaling Technology, Danvers, MA). Data acquisition was performed using (Attune NxT, Life Tech) flow cytometry, and the geometric fluorescent intensities and percent of positively stained cells were determined. More than 10000 events were acquired for each sample, and data analysis was performed using FCS Express version 4 (De Novo Software, Los Angeles, CA).

\subsection{Statistical Analysis}

Statistical analyses were performed using a repeated measure two-way ANOVA for all experiments with multiple time points. For experiments performed at only one time point, one-way ANOVAs were used. Statistical significance was determined by posthoc pairwise comparisons using Tukey tests. For pairwise comparisons, the means of each treatment group were compared. Differences were considered significant if $p \leq 0.05$ using the Prism software (Version 7, GraphPad, La Jolla, CA).

\section{RESULTS}

\subsection{Microparticle Characterization}

We characterized MPs generated using a single emulsion-solvent evaporation technique by assessing their size distributions, morphology, endotoxin levels, and $\zeta$-potentials. The size of fabricated MPs was assessed using dynamic light scattering (DLS). All formulations had average hydrodynamic diameters of approximately $1.14 \mu \mathrm{m}$ calculated by volume distribution (Figure 1A). Scanning electron microscopy of PLGA MPs illustrated the spherical shape and confirmed the relative diameter of all fabricated MPs to be about $1 \mu \mathrm{m}$ (Figure 1B). Endotoxin testing of the fabricated MPs confirmed the absence of activating levels of endotoxins on the MPs cocultured with DCs (Figure 1C). The endotoxin levels measured were negligible and not sufficient to drive maturation of DCs. ${ }^{42}$ All formulations of PLGA MPs demonstrated a negative $\zeta$-potential between -40 and $-20 \mathrm{mV}$ (Table 1 ).

\subsection{Uptake and Internalization of MPs by DCs}

In assessing the immunoeffect of the three different PLGA MP formulations, it is necessary minimize other confounding factors such as the rate of phagocytosis of MPs. First, confocal fluorescent microscopy was used to confirm the internalization of MPs by DCs (Figure 2A). For confocal microscopy, cell morphology was illustrated by tagging filamentous actin with a fluorescently conjugated phalloidin molecule. Fluorescein-loaded PLGA MPs were used to show particle localization within the cell. The confocal image (Figure 2A), with all planes included, demonstrates the internalization of the MPs by the DC and is representative for observations across all MP formulations.

Uptake of the three different MP formulations (PLG50, PLG75, and PL100) was measured using flow cytometry (Figure 2B). In these studies, cells were stained with the fluorescent dye, $\mathrm{DiD}$, and then incubated with rhodamine 6G-loaded MPs. At 1, 4, and $8 \mathrm{~h}$ the cells 
were analyzed by flow cytometry. Cellular uptake levels were determined based on the MP fluorescence associated with the cells compared to that of total cells. We saw no significant differences in MP uptake between PLG50, PLG75, and PL100 at these time points, which is generally the time period when phagocytosis occurs. ${ }^{43}$

\subsection{Effect of PLGA Molecular Ratio on Dendritic Cell Maturation}

To assess the effect of molecular ratio on the immunogenicity of PLGA, we examined the effect of PLGA MPs on DC maturation at time points ranging from 6 to $120 \mathrm{~h}$. Specifically, the major histocompatibility complex-II (MHCII) and costimulatory molecules - CD80 and CD86 were chosen as molecular markers for assessing DC maturation status. These markers are required for DCs to activate $\mathrm{T}$ cells against their receptor antigen, and thus are suitable targets for gauging the immunomodulatory effect of a biomaterial on DCs. Bone marrowderived DCs were cocultured with PLG50, PLG75, and PL100 MPs for time points ranging from 6 to $120 \mathrm{~h}$. Control groups for this study included iDCs and DCs treated with the TLR-4 agonist, LPS. Throughout this manuscript, we report the expression of maturation markers for a treatment relative to the expression of that marker on untreated DCs at each time point. To further simplify the analysis, we report a composite maturation index (CMI), which is an unweighted average of the relative expressions of MHCII, CD80, and CD86 and can be used to succinctly depict the comparisons between treatment groups. ${ }^{30}$ Additionally, we provided individual plots of each maturation marker in the Supporting Information.

The effect of PLGA and PLA MPs on maturation status was determined for six time points (Figure 3B). In all time points, we saw a significant increase in CMI of the LPS-treated cells (positive control) compared to the immature and MP-treated DCs. At the shorter time points (6 and $24 \mathrm{~h}$ ), the MPs tested had negligible effects on maturation status with no significant difference between that of the cells treated with MPs and the untreated cells, with the exception of the PLG50 and PL100 MP-treated DCs after $24 \mathrm{~h}$ of incubation, which had decreased CMI compared to iDCs. Remarkably, longer incubation times resulted in decreased CMI for all MP formulations compared to the iDC group. Interestingly, we observed no significant differences in the maturation status of DCs between the different MP formulations. These results suggest that low molecular weight PLGA MPs in static culture are not an activating stimulus to DCs at any time point but rather have immunosuppressive effects at the subchronic exposure times and beyond, regardless of the lactic-to-glycolic acid content of the polymer.

\subsection{PLGA Microparticle-Laden Dendritic Cells Resist LPS-Induced Maturation}

To further investigate the immune response to PLGA MPs, we assessed DC maturation status after LPS challenge. These experiments, termed 'maturation resistance', were conducted in a similar manner to the maturation experiments. However, after MPs were incubated with DCs for the designated time period, MPs were removed via washes with PBS, and the cells were given fresh DC media supplemented with $1.5 \mu \mathrm{g} / \mathrm{mL}$ LPS for $24 \mathrm{~h}$. The expression levels of MHCII, CD80, and CD86 were again quantified using flow cytometry. The resulting CMIs are displayed in Figure 3C. 
In general, PLGA MPs have an immunosuppressive effect after LPS challenge, particularly with increased MP exposure time. Maturation resistance for 6 and $24 \mathrm{~h}$ MP incubation periods showed significantly higher maturation levels than that of iDCs but significantly lower than that of LPS-treated cells, irrespective of the ratio of lactic acid to glycolic acid in the MP formulations. Interestingly, the CMI for the PLG50 formulation at $48 \mathrm{~h}$ was not significantly different from the iDC population. This trend continued for the later time points (72 $\mathrm{h}$ and beyond) for all MP formulations with one exception: DCs exposed to PLG75 for $96 \mathrm{~h}$ which had a substantially higher CMI than untreated DCs. Generally, there was no resistive effect by MP-treated DCs subsequently exposed to LPS for shortened MP incubation periods. Conversely, when cells are incubated with PLGA MPs (PLG50, PLG75, or PL100) for extended time periods, especially $72 \mathrm{~h}$ or longer, resistance to LPS-induced maturation was observed. These observations suggest that intracellular degradation of PLGA MPs may play a role in DC ability to resist maturation stimuli.

\subsection{PLGA Microparticle Uptake Decreases the Production of the Proinflammatory Cytokine IL-12}

As with TCR/MHCII recognition and costimulation by CD80/86, cytokine secretion is an important signal in the activation of T cells and influences the inflammatory environment. In these studies, we investigated the cytokine secretion of DCs following coculture with PLGA MPs of different monomeric constitution (PLG50, PLG75, and PL100). Microparticles were cocultured with bone marrow-derived DCs, and the supernatants were harvested and stored at $-20{ }^{\circ} \mathrm{C}$ until analysis. Additionally, DCs were exposed to the different MP formulations for varying times and then challenged with LPS for $24 \mathrm{~h}$. Interleukin- 12 was the cytokine of interest in these experiments (Figure 4). In general, matured DCs can be identified by increased expression and secretion of proinflammatory cytokines such as IL-12. ${ }^{44}$

The secretion of IL-12 after particle coculture, as well as after MP incubation and LPS challenge is shown in Figure 4. In the maturation experiments, we did not see any significant difference in IL-12 secretion between the iDC and the PLGA MP-treated DC groups at any time point assessed (Figure 4A). Additionally, there was a significantly higher secretion of IL-12 observed from the LPS-stimulated DCs compared to both iDCs and PLGA MP-treated DCs. The only exception was at the $120 \mathrm{~h}$ time point, which had no significant differences between any of the treatment groups. Further, we observed no substantial differences in IL-12 secretion between the different particle formulations. Inferentially, PLGA MP uptake does not stimulate IL-12 secretion from DCs.

After challenge with LPS, the immunosuppressive effects of PLGA MPs became more pellucid based on the IL-12 secretion profiles observed (Figure 4B). At 6 and $24 \mathrm{~h}$, we observed a significant increase in secretion of IL-12 in cells pretreated with PLGA MPs and challenged with LPS, compared to the iDC group. After $48 \mathrm{~h}$ of PLGA MP incubation, we observed a significant decrease in IL-12 secretion for all MP-treated DC groups, in comparison to LPS control. This trend held through to the $120 \mathrm{~h}$ time point, with two exceptions at the 72 and $96 \mathrm{~h}$ time points. Finally, there were no statistical differences in IL-12 secretion levels between the different particulate formulations. 


\subsection{Delayed Decrease in CCR7 Expression Following DC Uptake of PLGA MPs}

Crucial to immune system functionality, DCs migrate to the secondary lymphoid organs following phagocytosis of both foreign and self-material in the tissue microenvironment. ${ }^{45}$ To study the migratory potential of DCs following coculture with PLGA or PLA MPs, we investigated the expression of CCR7 as a phenotypic marker for DC migratory potential. We cocultured bone marrow-derived DCs with PLGA (PLG50, PLG75, and PL100) MPs. Immature DCs and DCs stimulated with poly[I:C[ were used as negative and positive controls, respectively. Poly[I:C] is a potent stimulator of CCR7 expression on DCs. ${ }^{46}$ The relative surface expressions of CCR7 normalized to the iDC population at 6,24 , and $72 \mathrm{~h}$ incubation time points are shown in Figure 5. At 6 and $24 \mathrm{~h}$ of MP exposure, CCR7 expression on MP-treated DCs remained comparable to that of iDCs. At the $24 \mathrm{~h}$ time point, there is a slight increase in the levels of CCR7 on DCs treated with MPs, for all formulations. Conversely, at $72 \mathrm{~h}$ post-incubation, the surface expression of CCR7 is significantly decreased compared to iDC levels.

\subsection{Suppression of T Cell Proliferation by MP-Treated DCs in a Mixed Lymphocyte Reaction}

The primary role of the DC is to bridge the adaptive and innate immune systems. In this respect, we wanted to test the allostimulatory capacity of DCs after coculture with PLGA MPs and additionally after LPS challenge. To determine the immunosuppressive effect of MP-treated DCs (from C57BL/6J mice), we quantified the relative proliferation of allogeneic, $\mathrm{BALB} / \mathrm{cByJ} \mathrm{CD} 4^{+} \mathrm{T}$ cells when cocultured in a mixed lymphocyte reaction (MLR). Dendritic cells were treated with PLG50, PLG75, or PL100 MPs for $48 \mathrm{~h}$ and then either cocultured with $\mathrm{T}$ cells or challenged with LPS for $24 \mathrm{~h}$ before addition of $\mathrm{T}$ cells. Microparticles and/or LPS were removed from culture wells prior to the addition of allogeneic, splenic $\mathrm{CD} 4^{+} \mathrm{T}$ cells. Dendritic cells and $\mathrm{T}$ cells were cocultured together for an additional three days. The proliferation of $\mathrm{T}$ cells was quantified by CFSE dye dilution and expressed as the percent proliferating in the treatment group normalized to $\mathrm{CD} 4^{+} \mathrm{T}$ cells cultured alone (Figure 6). The control groups in this experiment were $\mathrm{T}$ cells only (negative) and $\mathrm{T}$ cells treated with PMA and ionomycin (positive), a T cell proliferation cocktail. Additional controls included T cells seeded with iDCs and with LPS-matured DCs.

As expected, there was significantly higher proliferation levels in the PMA/IONO-treated T cells compared to all other treatment groups. The control results show that allogeneic mismatch between DCs and T cells induced significant $\mathrm{T}$ cell proliferation, in comparison to baseline T cell only propagation. Further, DCs pretreated with LPS amplified this propagative effect. Dendritic cells treated with the PLG50, PLG75, and PL100 MPs decreased $\mathrm{T}$ cell proliferation modestly to about half the amount as iDCs, though the difference between iDCs and PLG50 and PLG75 treated cells was not significant. The exception was the PL100 composition, where we observed a significant decrease in the percent of proliferated T cells, in comparison to the iDC treatment. Moreover, there were no significant differences between the $\mathrm{T}$ cell only control and mixed lymphocyte cultures where DCs were pretreated with MP formulations only. As expected, MP-treated DCs that were challenged with LPS and then cocultured with T cells showed proliferation levels significantly higher than those of DCs that were only exposed to MPs for all PLGA MP 
formulations. Overall, there is congruence between these results and data from our maturation and maturation resistance studies in that exposure to PLGA MPs seems to decrease proliferative responses to established stimulatory sources.

\subsection{Lactic Acid Quantification during Coculture of DCs with PLGA MPs}

Our previous studies on DC maturation and their allostimulatory capacity lends evidence to our hypothesis that PLGA MPs have immunosuppressive properties. We next investigated whether those properties may be dependent on the accumulation, both intracellularly and extracellularly, of one of the breakdown components of PLGA. The predominant biological enantiomer of lactic acid, L-lactic acid, was quantified both intracellularly and extracellularly in culture using an enzyme-based assay (Figure 7). In both assays, PLGA MPs were added at a 10:1 MP:DC ratio. In this experiment, DCs were seeded at $1 \times 10^{6}$ cells/well. The supernatant was harvested at the designated time points, deprotonated, and assayed for lactic acid. In the intracellular assays, cells were washed and then harvested using EDTA. The cells were then lysed and deprotonated.

In this assay, we saw an accumulation of lactic acid both intracellularly and extracellularly when PLGA MPs of all three formulations were cocultured with DCs. Intracellularly, the level of the lactic acid in untreated, immature DCs remained at a steady state for the entire $120 \mathrm{~h}$ tested, while lactic acid in LPS-treated cells generally decreased from its initial concentration over that same time period. There was significant difference in the intracellular concentration of lactic acid in the PLGA MP treated cells compared to iDCs at the $96 \mathrm{~h}$ time point. When the lactic acid concentration was again measured at the $120 \mathrm{~h}$ time point, there was no significant difference in PLG50 and PLG75 MP-treated cells as compared to the iDC. Interestingly, the PL100 MP-treated cells maintained a lactic acid concentration significantly higher compared to that of iDCs. We did not observe a significant difference in the lactic acid concentration between the different formulations of PLGA. The total intracellular accumulation of lactic acid reached around $90 \mu \mathrm{M}$ after $120 \mathrm{~h}$ of incubation for the PLGA MP-treated cells (Figure 7A).

Assessment of the extracellular lactic acid content yielded similar trends (Figure 7B). In these experiments, we discerned a significant increase in L-lactic acid concentration in the culture media of DCs treated with PLGA MPs. We also observed increasing lactic acid concentration with respect to time in the iDC population, which is consistent with a previous report. ${ }^{34}$ In general, the extracellular lactic acid concentration exceeded the intracellular concentration for all groups by almost three orders of magnitude, particularly for the PLGA MP-treated groups. This may be attributed to the unphagocytosed MPs in solution that are hydrolyzed in the aqueous culture media. Two-way ANOVA followed by pairwise comparisons using means from each treatment group showed significant differences in lactic acid concentration between all formulations of PLGA MPs and iDCs at the 96 and $120 \mathrm{~h}$ incubation time points. There was no significant difference in lactic acid accumulation between any of the MP formulations at any time point assessed. These results hint that the accumulation of lactic acid could be the driving factor behind the immunosuppressive behavior observed in DCs that have been treated with PLGA MPs of varying composition. 


\subsection{Sodium-L-lactate Promotes Downregulation of Immunostimulatory Molecules}

Our results from the lactic acid accumulation studies indicated that the monomeric components of PLGA accumulate both intracellularly and extracellularly in MP cocultures with DCs. To further support our central hypothesis, we added varying concentrations of sodium-L-lactate (sLA) to DC culture media and assessed the maturation status at time points ranging from $24-120 \mathrm{~h}$ (Figure $8 \mathrm{~A}$ ). The DC media is buffered around $\mathrm{pH} 7.4$, so the sodium-lactate is expected to remain deprotonated in media. Again, we report the composite maturation index, an unweighted average of the expression of CD86, CD80, and MHCII normalized to the iDC group, as a measure of maturation.

In general, we observed decreased expression of maturation markers at higher concentrations ( $\sim 50-100 \mathrm{mM})$ of sLA after longer hours of incubation. Moreover, the time dependent pattern of downregulation was similar to that detected for the MP maturation experiments. We observed a decreased maturation index in comparison to that of the iDC population starting at $120 \mathrm{~h}$ in the 50 and $100 \mathrm{mM}$ sLA. Taken altogether, our results suggest that soluble lactate has immunosuppressive capability and may be the key element driving the observed inhibitory effects on DCs from PLGA MPs.

\subsection{Soluble Sodium-L-lactate Induces Resistance to LPS Stimulation}

We also tested DCs resistance to LPS challenge for $24 \mathrm{~h}$ after pretreatment with sLA for the designated time points in Figure 8B. DCs were cultured with media supplemented with sodium-L-lactate at concentrations ranging from 1 to $100 \mathrm{mM}$ for the given time points. Following culture in lactic acid supplemented media, fresh media supplemented with 1.5 $\mu \mathrm{g} / \mathrm{mL}$ LPS was added to culture wells.

We observed significant resistance to LPS challenge from DCs incubated with 50 and 100 $\mathrm{mM}$ lactic acid. There was no significant difference between the composite maturation index between the 50 and $100 \mathrm{mM}$ lactic acid-treated cells and immature DCs after $120 \mathrm{~h}$ of coculture. More surprisingly, the $50 \mathrm{mM}$ sLA-treated cells and not the $100 \mathrm{mM}$ sLA-treated cells had similar maturation indexes as compared to that of iDCs at $96 \mathrm{~h}$. However, it is clear that both concentrations provide resistance to maturation via LPS. Moreover, there appears to be a time dependent effect of lactic acid at the lower concentrations, as no concentration of sLA provided maturation resistance at time points ranging from 24 to 72 , but various concentrations provide some resistance to maturation via LPS only after $96 \mathrm{~h}$ of coculture.

We assessed the intracellular concentration of L-lactic acid after treating DC with $100 \mathrm{mM}$ extracellular concentration for $120 \mathrm{~h}$. Incredibly, we determined the intracellular concentration was close to that found when DCs were incubated with MPs for $120 \mathrm{~h}$. This result provides strong evidence that at an undetermined intracellular concentration threshold, accumulated lactic acid downregulates DC maturation molecules irrespective of the lactic acid source (soluble or particulate form) (Figure 8C). 


\subsection{PLGA MP Uptake Downregulates Expression of the Nuclear Transcription Factor NF- $x B$}

To understand the downregulation of proinflammatory surface markers and the decreased production of proinflammatory IL-12 following DC ingestion of PLGA MPs, we examined the expression of NF- $x$ B in DCs that were treated with PLG50, PLG75, PL100, or $100 \mathrm{mM}$ sLA for 24,72 , and $120 \mathrm{~h}$ and then subsequently challenged with LPS. NF- $\kappa \mathrm{B}$ is a proinflammatory transcription factor which is critical for the transcription of stimulatory molecules CD80, CD86, and the proinflammatory cytokine IL-12. ${ }^{47}$ In these studies, we observed a downregulation of NF- $\kappa$ B after coculture with PLGA MPs or $100 \mathrm{mM}$ sLA, even with the subsequent LPS stimulation (Figure 9). The LPS-stimulated cells had expression of NF- $\kappa$ B significantly higher than that of either the iDC population or PLGA MP-treated cells at all time points. We also observed a time dependent suppression of NF- $x \mathrm{~B}$ expression in the $100 \mathrm{mM}$ sLA-treated cells, with their expression becoming significantly lower than iDCs only after $72 \mathrm{~h}$ of coculture.

\subsection{PLGA MPs Decrease the Phosphorylation of Key Proteins in the Canonical NF- $x B$ Activation Pathway}

Our previous results show that PLGA MPs downregulate the expression of inflammatory transcription factor NF- $\kappa \mathrm{B}$, thus leading to resistance from LPS-induced maturation. To shed light on these observations and further elucidate the effect of lactic acid, we performed a phosphorylated protein analysis of a couple of key molecules in the NF- $x$ B canonical pathway, transforming growth factor beta-activated kinase-1 (TAK1) and inhibitor of nuclear factor $k$ B kinase subunit beta (IKK $\beta$ ). Following incubation with PLGA MPs or $100 \mathrm{mM}$ sLA for the designated time period, DCs were stimulated with LPS for $24 \mathrm{~h}$. As controls, two DC groups were also incubated with LPS for $24 \mathrm{~h}$ and then pulsed with small molecule inhibitors of TAK1 ((5Z)-7-oxozeaenol) and IKK $\beta$ (ML120B) for $2 \mathrm{~h}$. Following treatments, the levels of phosphorylation of TAK1 and IKK $\beta$ in DCs were determined via phosphorylation antibody staining and flow cytometry.

Flow cytometric analysis revealed that low molecular weight PLGA MPs decreased the phosphorylation of TAK1 at all time points observed compared to LPS-treated cells (Figure 10A). This decrease was comparable in magnitude to known small molecule inhibitor of TAK1, (5Z)-7-oxozeaenol. ${ }^{40}$ Moreover, $100 \mathrm{mM}$ sLA had the same effect, decreasing the phosphorylation of TAK1 to a level significantly lower than that of TAK1 at all time points observed. There was no significant difference in the phosphorylated TAK1 levels between DCs conditioned in $100 \mathrm{mM}$ sLA and the PLGA MP-treated cells at any time point.

However, in general, the decrease in phosphorylation of TAK1 in the $100 \mathrm{mM}$ sLA-treated cells was less dramatic.

We also probed the phosphorylation of IKK $\beta$ (an important regulator of the canonical NF$\kappa \mathrm{B}$ pathway, which is downstream of TAK1) in DCs after treatment with PLGA MPs and $100 \mathrm{mM}$ sLA (Figure 10B). In general, changes in the phosphorylation levels of IKK $\beta$ were not as stark as those seen with TAK1, particularly at the 24 and $72 \mathrm{~h}$ time points. Briefly, at the early time point, only the PLG75 formulation reduced the phosphorylation of IKK $\beta$ significantly compared to LPS-treated DCs. At the $72 \mathrm{~h}$ time point, PLG75, PL100, and 100 
mM sLA treatments all decreased IKK $\beta$ phosphorylation to significantly lower levels than DCs exposed to LPS. Although we did not observe significant differences from the LPStreated DCs in some of the treatment groups at the 24 and $72 \mathrm{~h}$ time points, there was some reduction in phosphorylation levels of IKK $\beta$ across all treatment groups. At the latest time point tested, $120 \mathrm{~h}$, we observed phosphorylation trends similar to those observed with TAK1, where all PLGA MP-treated DCs and $100 \mathrm{mM}$ sLA-treated DCs showed levels of IKK $\beta$ phosphorylation significantly lower than those of DCs treated with LPS. Again, we did not observe a significant difference between formulations of PLGA MPs or $100 \mathrm{mM}$ sLA at any time point. Furthermore, neither the PLGA MP-treated cells nor the $100 \mathrm{mM}$ sLA-treated cells were significantly different from the ML120B control at any time point.

\subsection{Molecular Weight of PLGA Affects the Degree of Immunosuppression}

Varying the molecular weight of PLGA has been utilized to tune the degradation and drug release properties of this polymer. In general, higher molecular weight polymers of the same lactic to glycolic acid ratio undergo slower degradation rates, which correlate to slower drug release rates. ${ }^{31}$ As such, we investigated the relationship between the PLGA molecular weight, indirectly the degradation rate of the polymer, and the maturation status of DCs cocultured with PLGA MPs. (Figure 11). To investigate the effect of molecular weight on immunogenicity, we used two different polymers with 50:50 ratios of lactic to glycolic acid, 5004A $\left(M_{\mathrm{w}} \sim 20 \mathrm{kDa}\right)$ and $5010\left(M_{\mathrm{w}} \sim 95 \mathrm{kDa}\right)$. In these experiments, iDCs, LPS-matured DCs, and PLG50 $\left(M_{\mathrm{w}} \sim 10 \mathrm{kDa}\right)$-treated DCs were used for comparison of results. Upon coculture, the molecular weight had a clear effect on maturation status of DCs. The higher molecular weight PLGA MPs failed to reduce expression of positive-stimulatory molecules to the same degree as that observed with the low molecular weight PLG50 MPs. Microparticles fabricated from the 5010 formulation were immunostimulatory at the $24 \mathrm{~h}$ time point, but the CMI of 5010-treated cells was no different from iDCs beyond $24 \mathrm{~h}$. It should be noted that DCs treated with 5004A and 5010 had a delayed decrease in maturation status compared to that of cells treated with the PLG50 formulation. The higher molecular weight PLGA MPs failed to significantly decrease the maturation status below that of iDCs at any time point assessed.

\section{DISCUSSION}

PLGA particulate systems have been identified as valuable tools in drug delivery for their biocompatibility, biodegradability, ease of fabrication, and drug encapsulation ability. 20,32,48-50 More recently, researchers have recognized the versatility of PLGA-based particulate systems as a potential immunotherapeutic tool for DC modulation. ${ }^{8,14}$ Dendritic cells are the sentinels of the immune system and play a critical role in controlling the adaptive immune response. Tolerogenic DC-based immunotherapies attempt to exploit the role of DCs as the bridge between the innate and adaptive immune system to tip the scale toward tolerance. For instance, autologous-derived DCs treated exogenously with vitamin D3, dexamethasone, and mono-phosphoryl lipid A (MPLA) to induce a semimature, tolerance-inducing phenotype (secretion of anti-inflammatory cytokines, low expression of CD80/86, MHCII, and CD40) have proven efficacious for clinical treatment of rheumatoid arthritis. ${ }^{51,52}$ However, pitfalls with this approach hinder exogenously generated tDC 
therapies from being translated to the clinic. One attractive alternative is in vivo DC modulation using PLGA MPs to deliver encapsulated tolerogenic factors that induce regulatory DC phenotypes. ${ }^{8,14,22}$ Encapsulation of tolerogenic factors using PLGA MPs that passively target DCs has proven efficacious at preventing hyperglycemia and inducing protective immunity in the type 1 diabetes mouse model. ${ }^{8}$

As this approach grows, the effect of PLGA on key immune cells, particularly DCs, needs to be fully elucidated. ${ }^{53-55}$ There is contradictory evidence on the effect of PLGA MPs on DC immune functionality. On the basis of previous studies, there seems to be a relationship between the PLGA exposure time and the immunophenotype of dendritic cells. For instance, studies that assess the immunophenotype of DC at shorter time points (ranging from immediate contact to $24 \mathrm{~h}$ ) show that PLGA upregulates the expression of CD86, increases the production of proinflammatory cytokines and the activation of the NALP3 inflammasome. ${ }^{25,28,29,56}$ On the other hand, studies that look beyond $24 \mathrm{~h}$ see negligible or decreased expression in CD80/86 and MHCII expression compared to that of iDCs. ${ }^{21,30}$ One plausible explanation for this lies in the hydrolysis of the ester bond linking lactic and glycolic acid in PLGA, a process that is hastened in the acidic phagolysosome of DCs. ${ }^{31}$ One of the monomers liberated, lactic acid, has been shown to induce the release of antiinflammatory cytokines in high density DC cultures and block inflammasome activation via the GPR81 receptor. ${ }^{57}$ Further, lactic acid is immunosuppressive in the tumor environment and inhibits the inflammatory response from tumor-resident DCs. ${ }^{34,58-60}$ Therefore, we hypothesized that upon incubation with DCs, PLGA MPs are phagocytosed and digested within the cell, resulting in the accumulation of intracellular lactic acid, which downregulates the immunophenotype of DCs. Additionally, we postulated that this increase in the lactic acid concentration inside the cell, and therefore any immunosuppressive effects, were dependent on the rate of accumulation of lactic acid from the polymer.

To test these hypotheses, we first prepared unloaded PLGA MPs with differing ratios of lactic acid (PLG50, PLG75, and PL100) but of a constant low molecular weight ( 10 kDa). We also prepared higher molecular weight PLGA MPs (5004A and 5010) which had a constant molecular ratio (50:50) using an oil/water emulsion-solvent evaporation method. We fabricated MPs for all formulations with a hydrodynamic diameter of approximately 1 $\mu \mathrm{m}$. These MPs were efficiently taken up by DCs, as confirmed via flow cytometry and confocal microscopy. ${ }^{14,30}$ Unsurprisingly, these MPs (PLG50, PLG75, and PL100) were phagocytosed at similar rates. These findings helped to narrow the focus of our investigation. Although we did not compare the uptake of higher molecular weight PLGA MPs 5004A and 5010 to PLG50, PLG75, and PL100 MPs, it is generally believed that other physicochemical characteristics such as surface charge, and bio-functionalization affect phagocytic uptake more than molecular weight. ${ }^{61-63}$ As such, the phagocytic rates of the high molecular weight MPs should not vary widely from those observed for the PLG50, PLG75, and PL100 MPs.

Conventionally, the immunophenotype of DCs is determined by examining the expression of positive stimulatory molecules. Thus, we investigated the expression of MHCII, CD80, and CD86 as measures of maturation and CCR7 to assess the migratory potential in DCs cocultured with PLGA MPs. ${ }^{5,25,64}$ We also investigated the ability of DCs to resist 
maturation to LPS after being cocultured with PLGA MPs for between 6 and $120 \mathrm{~h}$. In these studies, we observed that the lower molecular weight PLGA MPs tested (PLG50, PLG75, and PL100) significantly decreased the composite maturation index (un-weighted average of the expression of MHCII, CD80, and CD86) with respect to the immature DCs, starting at $48 \mathrm{~h}$ and continuing to $120 \mathrm{~h}$. These results suggest that low molecular weight PLGA is immunosuppressive and may be well suited for nonactivating applications and scenarios where immune dampening is desired. This immunosuppressive nature of PLGA is also time dependent, as its effects are not detected until $48 \mathrm{~h}$. One possible explanation for the results observed in the MP incubation experiments is that PLGA provides short-term contact activation of DCs, as shown by Yoshida et al. ${ }^{28}$ When DCs are cocultured with 75:25 PLGA MPs at a 5:1 MP to cell ratio ( $~ 80 \mathrm{kDa}$ polymer $\left.M_{\mathrm{W}}\right)$, IL-6 and TNF- $a$ secretion is increased compared to immature DC populations. However, the same study reports that after $24 \mathrm{~h}$ of PLGA/DC coculture, no significant difference in the expression of CD80 and CD86 is observed. Considering this observation and our findings, PLGA MPs may provide shortterm activation, which is reversed as MPs remain resident in the intracellular spaces of DCs and begin to degrade. Additionally, the discrepancies between this study and that of Yoshida et al. may be attributed to the difference in molecular weight, and thus rate of breakdown, of the polymers chosen.

Dendritic cells were also challenged with LPS after coculture with low molecular weight PLGA MPs for periods between 6 and $120 \mathrm{~h}$. Impressively, we observed the manifestation of the same immunosuppressive behavior of low molecular weight PLGA (PLG50, PLG75, and PL100) even after LPS challenge. After $72 \mathrm{~h}$, the PLGA MP-treated DCs that were challenged had maturation status similar to that of iDCs. In autoinflammatory conditions, DCs may be exposed to external stimuli that promote a mature phenotype. Therefore, in nonactivating applications, DCs with the ability to resist maturation may be advantageous in curbing the downstream immune response. The immunosuppressive nature of PLGA in the inflammatory environment was also highlighted by Tostanoski et al. and Kuo et al. in the experimental autoimmune encephalitis (EAE) model. ${ }^{19,65}$ In particular, Kuo et al. reported that PLGA nanoparticles $\left(500 \mathrm{~nm}, M_{\mathrm{W}} \sim 10 \mathrm{kDa}\right.$ ) surface functionalized with experimental autoimmune encephalomyelitis-relevant antigen (proteolipid protein) decreased the expression of costimulatory molecules and increased the expression of tolerogenic markers (PD-L1) on APCs. Moreover, in vivo, PLGA antigen-functionalized nano-particles significantly improved EAE prognosis in a dose dependent manner compared to nanoparticles conjugated with disease-irrelevant peptide. ${ }^{19}$ This study illustrated that PLGA MPs themselves can act as an immunoregulatory factor and, in combination with other tolerogenic factors, may synergize to promote arrest of autoimmune cascades. ${ }^{30}$

In addition to surface markers, the maturation state of DCs can also be distinguished by production of cytokines (signal 3). Stimulated DCs characteristically increase the secretion of IL-12 and polarize T cells toward a $\mathrm{T}_{\mathrm{H} 1}$ subtype. ${ }^{66}$ We characterized the IL-12 secretion of DCs treated with PLGA MPs or DCs treated with PLGA MPs and subsequently challenged with LPS for $24 \mathrm{~h}$. We observed that low molecular weight PLGA MP-treated DCs maintain IL-12 secretion levels similar to those of the immature DC population, irrespective of formulation. Furthermore, MP-treated, LPS-challenged DCs had IL-12 secretion significantly lower than that of LPS-matured DCs. This decrease in IL-12 hints at 
the ability of DCs treated with low molecular weight PLGA MPs to induce T cell anergy, an important mechanism of tolerance in the context of autoimmunity. Moreover, the low expression of immunostimulatory molecules and the low secretion of proinflammatory IL-12 from the PLGA MP-treated cells could also account for suppression of $\mathrm{T}$ cell proliferation in a mixed lymphocyte reaction with allogeneic T cells. Divergence in the IL-12 secretion profile of the PL100 MP-treated, LPS-matured DCs from that of the other formulations, particularly at time points past $96 \mathrm{~h}$, suggest that other variables may influence the immunosuppressive nature of this polyester. One possibility is the accumulation of glycolic acid, the other constituent of PLGA. The immunogenicity of glycolic acid is understudied but may be an important factor in the cytokine profile of DCs treated with PLGA MPs. ${ }^{67,68}$ Notably, we observed a general increase in the level of secretion of IL-12 in untreated and MP-treated DCs with time (Figure 4A), particularly evident at the later time points. Though insignificant, this increase may hint at the balance between immunostimulatory and immunoinhibitory pathways to maintain immune homeostasis in immune cells.

Consistent with our observations on costimulatory molecule and MHC II expression, lengthy incubation with PLGA MPs also downregulated the expression of the migratory marker CCR7. This finding is important, especially in the context of DC immunotherapy. In a study by Lewis et al., fluorescent PLGA MPs $\left(M_{\mathrm{w}} \sim 20 \mathrm{kDa}\right)$ were injected into the hock of the paw of mice. Subsequently, the popliteal LNs were analyzed for DCs that had phagocytosed fluorescently loaded PLGA MPs. ${ }^{69}$ This study reported that the highest number of fluorescence-associated DCs (i.e., DCs that had phagocytosed PLGA MPs) occurred at $48 \mathrm{~h}$ after subcutaneous injection, suggesting the highest rate of traffcking of DCs to the LNs occurs within a $48 \mathrm{~h}$ time period. Herein, we report that PLGA MPs dampened expression of CCR7 at $72 \mathrm{~h}$, indicating that low molecular weight PLGA MP formulations may not deter DC locomotion to these lymphocyte-rich areas.

One subhypothesis of this project was that the lactic:glycolic acid content of the polymer could influence DC immunophenotype. In general, the hydrophobicity of PLGA MPs is affected by the ratio of lactic to glycolic acid in the polymeric composition. The methyl group on lactic acid provides additional hydrophobicity to the polymer, thus a higher ratio of lactic to glycolic acid results in a higher degree of hydrophobicity. The current perception is that the more hydrophobic the PLGA, the slower it breaks down in aqueous media, which would correspond to higher immunoactivation. ${ }^{29,31}$ Thus, we hypothesized that maturation responses would differ between the different PLGA formulations, the more hydrophobic particles showing a higher maturation status due to less lactic acid accumulation. In these studies, the formulation of PLGA did not affect the maturation status which gives us new insight that is somewhat contradictory to previous reports. ${ }^{21,28-30,70}$ However, it should be noted that the molecular weights of PLGA used in previous reports were higher than molecular weight of PLGA MPs discussed thus far. The similarities observed in the immunomodulatory effects between the PLG50, PLG75, and PL100 MPs is perhaps surprising given the importance of lactic:glycolic acid ratio to the hydration and degradation of the raw polymer. ${ }^{71}$ There are a couple factors that could explain the observed results and the similar release of lactic acid from the PLG50, PLG75, and PL100 MPs. The first is the common molecular weight of the polymers $(\sim 10 \mathrm{kDa})$, generally regarded as rapidly degrading. ${ }^{71}$ Low molecular weight polymers of PLGA do not exhibit the predicted 
macromolecular bond hydrolysis during degradation, suggesting that the contribution from polymer composition (lactic:glycolic acid ratio) to degradation may be insignificant in these studies. ${ }^{72}$ Second, after the hydration stage of the polymer, PLGA tends to enter a biodegradation stage that is constant regardless of the polymer composition. ${ }^{73}$ Lastly, degradative studies on PLGA do not mimic the harsh microenvironment of the phagolysosome. This further complicates the degradation rate, adding conditions such as $\mathrm{pH}$, which is known to increase the degradation rate at lower values, and enzymatic activity as important factors. ${ }^{74}$ Altogether, the discrepancies between our study and the results reported by Yoshida et al. may be attributed to the difference in molecular weight and, indirectly, hydrolysis rates of the polymers used.

As such, we also investigated the impact of PLGA molecular weight on the immunogenicity of DCs. It is generally known that higher molecular weight polymers have slower degradation rates. ${ }^{31}$ Additionally, it has been reported that higher molecular weight PLGA polymers also produce MPs that prompt positive stimulatory responses in immune cells. ${ }^{27,28}$ We believe that this stimulatory effect is inversely related to the accumulation of monomeric lactic acid from polymer degradation. In our study, the lactic acid accumulation of the higher molecular weight PLGA (5004A and 5010) was not assessed, nor was the effect of the terminal chemistry of the polymer. However, any modulatory effects from the polymer termination chemistry are expected to be insignificant, especially compared to those from the molecular weight of the polymer. On the other hand, it has been reported that molecular weight of PLGA MPs has a large influence on the degradation rate. In a study by Park, PLG50 MPs of molecular weights $17 \mathrm{kDa}$ and $41 \mathrm{kDa}$ were synthesized and their degradation rates in PBS characterized. Conclusively, this study illustrated that the larger the PLGA molecular weight, the slower the degradation. Larger molecular weight PLGA MPs release larger oligomers of lactic/glycolic acid from their bulk MP mass. These larger oligomers then in turn are degraded to its monomeric constituents, which takes longer than a shorter PLGA chain.

As previously mentioned, one particularly interesting observation in the manuscript by Yoshida et al. was the contact dependent activation of DCs immediately following uptake of PLGA MPs. ${ }^{28}$ Our findings are in agreement with this previously reported early activation following DC contact with MPs. However, at longer incubation times, the monomeric composition of MPs may have the greatest influence on the immunophenotype of DCs. For instance, Sharp et al. conducted similar experiments with polystyrene MPs and showed decreased secretion of IL- $1 \beta$ in response to LPS challenge when MP incubation times were extended. ${ }^{56}$ This article provided some evidence that the dimensionality and physical characteristics of the microparticle may provide initial activation, which may be reversed later on as the polymer is degraded. Accordingly, investigation of the effects of accumulation of the constituent molecules of PLGA in DCs is relevant to deciphering the effects of PLGA MPs on these specialized immune cells.

Correlating closely with the temporal decrease in maturation status of DCs cocultured with PLGA MPs, we observed an increase in lactic acid both intracellularly and extracellularly after MPs were cocultured with DCs. Interestingly, there was not a significant difference between the accumulation of lactic acid, both extracellularly and intracellularly, after $120 \mathrm{~h}$ 
of incubation between the PLG50, PLG75, and PL100 MP formulations. This suggests that the hydrophobic effects that were previously reported to affect degradation may have less influence when examining PLGA degradation over longer time points. Further, polymer degradation kinetics is certainly altered in the acerbic environment of the phagolysosome, which may hasten particle degradation and outweigh the influence of the varying hydrophobicity of the MP formulations.

Generally, the flux of lactic acid in the cell is controlled by monocarboxylate transporters (MCTs). Monocarboxylate transporters control the accumulation of lactic acid intracellularly by cotransporting lactate and protons out of the cell. ${ }^{59}$ However, the efficiency of MCTs is heavily influenced by the lactate concentration gradient across the cell membrane, both the intracellular and extracellular $\mathrm{pH}$, and the concentration of other MCT substrates (e.g., pyruvate, ketone bodies, $\beta$-hydroxybuty-rate). Thus, in static culture, the increase in extracellular lactic acid (from hydrolysis of PLGA in aqueous solution) may disrupt the transport of lactic acid out of the cell.

Investigating this phenomenon further, we added sLA at different concentrations to the culture media of DCs and assessed their immunophenotype over the course of 5 days. Previously, Nasi et al. reported that lactic acid accumulation in DC cultures exhibits a strong inhibitory effect on inflammatory DC differentiation. ${ }^{34}$ Moreover, they suggested that the lactic acid accumulation in the supernatant of dense DC cultures is similar to that of the extracellular concentration in the tumor microenvironment $(\sim 40 \mathrm{mM})$ after $4-6$ days of culture..$^{34,59}$ Building on this, we observed that high concentrations of sLA (50-100 mM) had a similar immunosuppressive effect. Interestingly, at these high levels of extracellular lactic acid, the intracellular lactic acid concentration is similar to that engendered by MP incubations after $120 \mathrm{~h}$, suggesting that the flux of lactic acid into the DC far exceeds its rate of expulsion by active transport means (MCTs and other transport channels), which results in the accumulation of lactic acid intracellularly at high extracellular concentrations. In general, the observed increase in lactic acid correlated well with a decrease in the composite maturation index. However, we observed a significantly lower CMI in the PLGA MP-treated DCs compared to iDCs before we detect a significant difference in the accumulation of lactic acid between the different populations. One possible explanation for this discrepancy could be the accumulation of glycolic acid, which was not investigated in this report. It has been reported that glycolic acid is metabolized to glyoxylic acid, which may then be converted to glycine. ${ }^{75}$ Glycine has been found to protect against shock from endotoxin, which could also explain the resistance to maturation that PLGA provides. ${ }^{76}$ This hypothesis, along with the effect of glycolic acid on IL-12 secretion, will be explored in future studies.

With regards to monomeric lactic acid, there are competing postulates on how it influences immune cell polarity. Lactic acid is a key byproduct in cellular glycolysis, and is a key signaling molecule in regulating cellular metabolism. Interestingly, endothelial cells exposed to lactic acid levels commonly found in the tumor microenvironment saw an increased concentration of intracellular lactic acid and activation of hypoxia induced factor-1 (HIF1).

77 This activation of HIF1, which is critical for the transcription of many of the glycolytic enzymes, may shift the balance of metabolism away from the Krebs's cycle, reducing the 
flux of metabolites through oxidative phosphorylation. This reduction in key metabolites (e.g., Acetyl-CoA) reduces the ability of the cell to expand its endoplasmic reticulum and rapidly produce functional inflammatory proteins. ${ }^{78}$

Others have proposed that the acidity derived from lactic acid may drive immune cell activation. Lactic acid has a $\mathrm{p} K_{\mathrm{a}}$ around 3.9 and therefore, is a proton donor. Lactic acid, as the primary acidic byproduct of the Warburg effect, lowers the $\mathrm{pH}$ of tumor extracellular microenvironment to $6.0-6.5 .{ }^{79}$ Moreover, it has been shown that mild acidification of innate immune cells can activate the inflammasome ${ }^{80}$ In this study by Rajamaki et al., bone marrow-derived macrophages were grown at acidic $\mathrm{pH}$ and assessed for IL- $1 \beta$ secretion. At acidic $\mathrm{pH}$, more IL- $1 \beta$ was detected in the supernatant, as a result of inflammasome activation. However, this study was conducted in a short time range, with incubation in an acidic environment only lasting 1-16 h. Additionally, these cells were preactivated with LPS to boost IL- $1 \beta$ secretion. In nonprimed cells, no increase in the proinflammatory cytokine secretion was observed. To address $\mathrm{pH}$ in this experiment, we recorded the $\mathrm{pH}$ in the DC/MP or DC/sLA cocultures (Figure S1). On the basis of our studies, the DC culture media along with $\mathrm{CO}_{2}$ incubation effectively buffer all $\mathrm{pH}$ change as a result of lactic acid build up; therefore, the immunomodulatory effects of lactic acid are not derived from its proton donating ability.

Moreover, our results suggest that intracellular lactic acid accumulation may subjugate any immune activation stimulated by extracellular acidosis, which is buttressed by a study completed by Kreutz and coworkers. Briefly, they examined the global gene expression patterns of LPS-activated monocytes cultured in physiological levels of lactic acid or acidic $\mathrm{pH}$ for up to four hours. They found that lactic acid delayed or inhibited the expression of many LPS-induced genes. This inhibitory effect on inflammatory gene expression was not observed under acidic conditions. Moreover, this group identified some of the key molecular players that may be tempered by lactic acid, including the nuclear transcription factor NF$\kappa \mathrm{B} .{ }^{60}$ Activation of NF- $\kappa \mathrm{B}$ leads to the expression of other proinflammatory genes including proinflammatory cytokines, chemokines, and adhesion molecules. ${ }^{81,82}$

Herein, we investigated the impact of low molecular weight PLGA MP and $100 \mathrm{mM}$ sLA coincubation on DC expression of this critical transcription factor. We observed a significant downregulation of NF- $x$ B in LPS-matured, bone marrow-derived DCs upon coculture with PLGA MPs or $100 \mathrm{mM}$ sLA.

Downregulation of this specific transcription factor sheds light on the mechanism(s) through which PLGA may induce an immunosuppressive phenotype, as NF- $\kappa \mathrm{B}$ is involved in the transcription of the genes for immunostimulatory surface proteins (CD80/CD86). ${ }^{85,86}$ Moreover, it provides further credence that accumulation of PLGA MP-derived lactic acid generates the immunoinhibitory effects. Interestingly, the sLA treated cells in this experiment displayed a slower response in downregulation of NF- $\kappa$ B compared with that of particle-treated cells. These results suggest that lactic acid may accumulate quicker inside the cell when introduced in the particulate form over the soluble form, although the accumulation of intracellular lactic acid over time in sLA-treated cells was not measured in this manuscript. These results suggest a plausible mechanism of PLGA MP action. 
Additionally, NF- $\kappa \beta$ is often a therapeutic target in autoinflammatory conditions; thus, PLGA MP-based systems may provide additional benefit beyond the delivery of encapsulated, immunomodulatory payloads. ${ }^{87}$

Finally, we considered if a deficit in phosphorylation of key molecular signatures could be involved in the observed lactic acid-driven obstruction of the canonical NF- $\kappa$ B pathway. Moreover, we were able to identify a potential mechanism by which PLGA acts on the LPSinduced, NF- $\kappa$ B pathway. Our results suggest that lactate derived from PLGA MPs blocks the phosphorylation of TAK1, an early signature for activation of NF- $\kappa$ B. We also observed diminished phosphorylation of IKK $\beta$, a critical subunit of the kinase required to remove the 'brakes' from NF- $\kappa \mathrm{B}$, by all low molecular weight, PLGA MP formulations at the $120 \mathrm{~h}$ time point. However, it is not clear if this diminution of IKK $\beta$ phosphorylation is due to direct inhibition by lactic acid or the action of lactic acid on earlier actors in the cascade (e.g., TAK1). ${ }^{83}$ Another confounding factor in this study, which may have contributed to the belated observation of significant decreases in IKK $\beta$ phosphorylation, is the antibody used to probe the phosphorylation of IKK $\beta$. This antibody has some reactivity toward inhibitor of nuclear factor $\alpha$ B kinase subunit alpha (IKK $a$ ). Inhibitor of IKK $a$ plays a role in both the canonical and noncanonical activation of NF- $\kappa$ B. Therefore, the observed results may be indicative of both IKK $\beta$ and IKK $a$ phosphorylation. ${ }^{84}$ Regardless, the overall trend of phosphor-ylation levels of IKK $\beta$ at the various time points indicates that there is indirect or direct inhibition of IKK $\beta$ activation by lactate.

\section{CONCLUSIONS}

In designing biomaterial-based bioengineering systems for therapeutic or regenerative purposes, it is critical that we have a comprehensive understanding of the effects of the biomaterial on the immune system. The biocompatibility, ease of fabrication, biodegradability, and other desirable qualities have made PLGA the most studied biomaterial for potential applications in drug delivery, tissue engineering and, more recently, immunotherapy. However, the full effect of this biomaterial on immune cells is yet to be fully elucidated.

In this study, we advance the current knowledge on the immunomodulatory capacity of PLGA. Specifically, we investigated the effect of PLGA MPs on the immunophenotype of murine bone marrow-derived dendritic cells at acute and subchronic time points. Our findings indicate that following coculture with PLGA MPs, hydrolysis of the PLGA MPs releases lactic acid into the intracellular space, which ultimately results in an inhibitory phenotype and resistance to maturation. To further corroborate these results, we investigated the effect of sLA on dendritic cells and found that sLA induced similar immunosuppressive effects as PLGA MPs. Finally, we discovered that lactic acid modulation of the critical transcription factor NF-k $\beta$, through inhibition of the TAK1 kinase, may be at the center of the observed downregulation of positive stimulatory mediators in PLGA MP-treated DCs.

This study also elucidates how the immunomodulatory nature of PLGA varies with the physicochemical characteristics of the polymer, particularly the molecular weight. It further highlights the need for careful selection and engineering of PLGA to suit the desirable 
application. Therefore, we submit that for tolerogenic applications, low molecular weight polymers of PLGA may be used as a safe, biocompatible, and immunosuppressive agent.

\section{Acknowledgments}

The authors gratefully thank Dr. Soichiro Yamada for his time, reagents, and help in acquiring the confocal microscopy images. We gratefully acknowledge the support of this work by Grant R35GM125012 from the National Institutes of Health.

\section{References}

1. Savina A, Amigorena S. Phagocytosis and antigen presentation in dendritic cells. Immunol Rev. 2007; 219:143-56. [PubMed: 17850487]

2. Slawek A, Maj T, Chelmonska-Soyta A. CD40, CD80, and CD86 costimulatory molecules are differentially expressed on murine splenic antigen-presenting cells during the pre-implantation period of pregnancy, and they modulate regulatory $\mathrm{T}$ cell abundance, peripheral cytokine response, and pregnancy outcome. Am J Reprod Immunol. 2013; 70(2):116-26. [PubMed: 23445188]

3. Villadangos JA, Schnorrer P, Wilson NS. Control of MHC class II antigen presentation in dendritic cells: a balance between creative and destructive forces. Immunol Rev. 2005; 207:191-205. [PubMed: 16181337]

4. Sallusto F, Schaerli P, Loetscher P, Schaniel C, Lenig D, Mackay CR, Qin S, Lanzavecchia A. Rapid and coordinated switch in chemokine receptor expression during dendritic cell maturation. Eur J Immunol. 1998; 28(9):2760-9. [PubMed: 9754563]

5. Forster R, Davalos-Misslitz AC, Rot A. CCR7 and its ligands: balancing immunity and tolerance. Nat Rev Immunol. 2008; 8(5):362-71. [PubMed: 18379575]

6. Lewis JS, Allen RP. An introduction to biomaterial-based strategies for curbing autoimmunity. Exp Biol Med (London, U K). 2016; 241(10):1107-15.

7. Hu J, Wan Y. Tolerogenic dendritic cells and their potential applications. Immunology. 2011; 132(3):307-14. [PubMed: 21208205]

8. Lewis JS, Dolgova NV, Zhang Y, Xia CQ, Wasserfall CH, Atkinson MA, Clare-Salzler MJ, Keselowsky BG. A combination dual-sized microparticle system modulates dendritic cells and prevents type 1 diabetes in prediabetic NOD mice. Clin Immunol. 2015; 160(1):90-102. [PubMed: 25842187]

9. Anderson AE, Swan DJ, Wong OY, Buck M, Eltherington O, Harry RA, Patterson AM, Pratt AG, Reynolds G, Doran JP, Kirby JA, Isaacs JD, Hilkens CM. Tolerogenic dendritic cells generated with dexamethasone and vitamin D3 regulate rheumatoid arthritis CD4+ T cells partly via transforming growth factor-beta1. Clin Exp Immunol. 2017; 187:113. [PubMed: 27667787]

10. Schuler G, Romani N. Generation of mature dendritic cells from human blood. An improved method with special regard to clinical applicability. Adv Exp Med Biol. 1997; 417:7-13. [PubMed: 9286330]

11. Giannoukakis N, Phillips B, Finegold D, Harnaha J, Trucco M. Phase I (safety) study of autologous tolerogenic dendritic cells in type 1 diabetic patients. Diabetes Care. 2011; 34(9):202632. [PubMed: 21680720]

12. Ludewig B, McCoy K, Pericin M, Ochsenbein AF, Dumrese T, Odermatt B, Toes RE, Melief CJ, Hengartner H, Zinkernagel RM. Rapid peptide turnover and inefficient presentation of exogenous antigen critically limit the activation of self-reactive CTL by dendritic cells. J Immunol. 2001; 166(6):3678-87. [PubMed: 11238607]

13. Cruz LJ, Tacken PJ, Rueda F, Domingo JC, Albericio F, Figdor CG. Targeting nanoparticles to dendritic cells for immunotherapy. Methods Enzymol. 2012; 509:143-63. [PubMed: 22568905]

14. Jhunjhunwala S, Raimondi G, Thomson AW, Little SR. Delivery of rapamycin to dendritic cells using degradable microparticles. J Controlled Release. 2009; 133(3):191-7.

15. Rescigno M, Borrow P. The host-pathogen interaction: new themes from dendritic cell biology. Cell. 2001; 106(3):267-70. [PubMed: 11509175] 
16. Lewis JS, Roy K, Keselowsky BG. Materials that harness and modulate the immune system. MRS Bull. 2014; 39(1):25-34. [PubMed: 26997752]

17. Phanse Y, Carrillo-Conde BR, Ramer-Tait AE, Roychoudhury R, Pohl NL, Narasimhan B, Wannemuehler MJ, Bellaire BH. Functionalization of polyanhydride microparticles with dimannose influences uptake by and intracellular fate within dendritic cells. Acta Biomater. 2013; 9(11):8902-9. [PubMed: 23796408]

18. Conniot J, Silva JM, Fernandes JG, Silva LC, Gaspar R, Brocchini S, Florindo HF, Barata TS. Cancer immunotherapy: nanodelivery approaches for immune cell targeting and tracking. Front Chem. 2014; 2:105. [PubMed: 25505783]

19. Kuo R, Saito E, Miller SD, Shea LD. Peptide-Conjugated Nanoparticles Reduce Positive Costimulatory Expression and T Cell Activity to Induce Tolerance. Mol Ther. 2017; 25:1676. [PubMed: 28408181]

20. Elamanchili P, Diwan M, Cao M, Samuel J. Characterization of poly(D,L-lactic-co-glycolic acid) based nanoparticulate system for enhanced delivery of antigens to dendritic cells. Vaccine. 2004; 22(19):2406-12. [PubMed: 15193402]

21. Waeckerle-Men Y, Scandella E, Uetz-Von Allmen E, Ludewig B, Gillessen S, Merkle HP, Gander B, Groettrup M. Phenotype and functional analysis of human monocyte-derived dendritic cells loaded with biodegradable poly(lactide-co-glycolide) microspheres for immunotherapy. J Immunol Methods. 2004; 287(1-2):109-24. [PubMed: 15099760]

22. Cho JJ, Stewart JM, Drashansky TT, Brusko MA, Zuniga AN, Lorentsen KJ, Keselowsky BG, Avram D. An antigen-specific semi-therapeutic treatment with local delivery of tolerogenic factors through a dual-sized microparticle system blocks experimental auto-immune encephalomyelitis. Biomaterials. 2017; 143:79-92. [PubMed: 28772190]

23. Saluja SS, Hanlon DJ, Sharp FA, Hong E, Khalil D, Robinson E, Tigelaar R, Fahmy TM, Edelson RL. Targeting human dendritic cells via DEC-205 using PLGA nanoparticles leads to enhanced cross-presentation of a melanoma-associated antigen. Int J Nanomed. 2014; 9:5231-46.

24. Wischke C, Zimmermann J, Wessinger B, Schendler A, Borchert HH, Peters JH, Nesselhut T, Lorenzen DR. Poly(I: C) coated PLGA microparticles induce dendritic cell maturation. Int J Pharm. 2009; 365(1-2):61-8. [PubMed: 18812217]

25. Park J, Babensee JE. Differential functional effects of biomaterials on dendritic cell maturation. Acta Biomater. 2012; 8(10):3606-17. [PubMed: 22705044]

26. Nicolete R, dos Santos DF, Faccioli LH. The uptake of PLGA micro or nanoparticles by macrophages provokes distinct in vitro inflammatory response. Int Immunopharmacol. 2011; 11(10):1557-1563. [PubMed: 21621649]

27. Yoshida M, Babensee JE. Differential effects of agarose and poly(lactic-co-glycolic acid) on dendritic cell maturation. J Biomed Mater Res, Part A. 2006; 79(2):393-408.

28. Yoshida M, Mata J, Babensee JE. Effect of poly(lactic-co-glycolic acid) contact on maturation of murine bone marrow-derived dendritic cells. J Biomed Mater Res, Part A. 2007; 80(1):7-12.

29. Liu Y, Yin Y, Wang LY, Zhang WF, Chen XM, Yang XX, Xu JJ, Ma GH. Surface hydrophobicity of microparticles modulates adjuvanticity. J Mater Chem B. 2013; 1(32):3888-3896.

30. Lewis JS, Roche C, Zhang Y, Brusko TM, Wasserfall CH, Atkinson M, Clare-Salzler MJ, Keselowsky BG. Combinatorial delivery of immunosuppressive factors to dendritic cells using dual-sized microspheres. J Mater Chem B. 2014; 2(17):2562-2574. [PubMed: 24778809]

31. Makadia HK, Siegel SJ. Poly Lactic-co-Glycolic Acid (PLGA) as Biodegradable Controlled Drug Delivery Carrier. Polymers (Basel, Switz). 2011; 3(3):1377-1397.

32. Jiang W, Gupta RK, Deshpande MC, Schwendeman SP. Biodegradable poly(lactic-co-glycolic acid) microparticles for injectable delivery of vaccine antigens. Adv Drug Delivery Rev. 2005; 57(3):391-410.

33. Wischke C, Schwendeman SP. Principles of encapsulating hydrophobic drugs in PLA/PLGA microparticles. Int J Pharm. 2008; 364(2):298-327. [PubMed: 18621492]

34. Nasi A, Fekete T, Krishnamurthy A, Snowden S, Rajnavolgyi E, Catrina AI, Wheelock CE, Vivar N, Rethi B. Dendritic cell reprogramming by endogenously produced lactic acid. J Immunol. 2013; 191(6):3090-9. [PubMed: 23956421] 
35. Bronte V. Tumor cells hijack macrophages via lactic acid. Immunol Cell Biol. 2014; 92(8):647-9. [PubMed: 25091608]

36. Gottfried E, Kunz-Schughart LA, Ebner S, Mueller-Klieser W, Hoves S, Andreesen R, Mackensen A, Kreutz M. Tumor-derived lactic acid modulates dendritic cell activation and antigen expression. Blood. 2006; 107(5):2013-2021. [PubMed: 16278308]

37. Lewis JS, Dolgova NV, Chancellor TJ, Acharya AP, Karpiak JV, Lele TP, Keselowsky BG. The effect of cyclic mechanical strain on activation of dendritic cells cultured on adhesive substrates. Biomaterials. 2013; 34(36):9063-70. [PubMed: 24008042]

38. Zivkovic L, Akar B, Roux BM, Spremo Potparevic B, Bajic V, Brey EM. Investigation of DNA damage in cells exposed to poly (lactic-co-glycolic acid) microspheres. J Biomed Mater Res, Part A. $2017 ; 105(1): 284-291$.

39. Kruger NJ. The Bradford method for protein quantitation. Methods Mol Biol. 1994; 32:9-15. [PubMed: 7951753]

40. Wu J, Powell F, Larsen NA, Lai Z, Byth KF, Read J, Gu RF, Roth M, Toader D, Saeh JC, Chen H. Mechanism and in vitro pharmacology of TAK1 inhibition by (5Z)-7-Oxozeaenol. ACS Chem Biol. 2013; 8(3):643-50. [PubMed: 23272696]

41. Wen D, Nong Y, Morgan JG, Gangurde P, Bielecki A, Dasilva J, Keaveney M, Cheng H, Fraser C, Schopf L, Hepperle M, Harriman G, Jaffee BD, Ocain TD, Xu Y. A selective small molecule IkappaB Kinase beta inhibitor blocks nuclear factor kappaB-mediated inflammatory responses in human fibroblast-like synoviocytes, chondrocytes, and mast cells. J Pharmacol Exp Ther. 2006; 317(3):989-1001. [PubMed: 16525037]

42. Schwarz H, Schmittner M, Duschl A, Horejs-Hoeck J. Residual endotoxin contaminations in recombinant proteins are sufficient to activate human CD1c+ dendritic cells. PLoS One. 2014; 9(12):e113840. [PubMed: 25478795]

43. Thiele L, Merkle HP, Walter E. Phagocytosis and phagosomal fate of surface-modified microparticles in dendritic cells and macrophages. Pharm Res. 2003; 20(2):221-8. [PubMed: 12636160]

44. Krummen M, Balkow S, Shen L, Heinz S, Loquai C, Probst HC, Grabbe S. Release of IL-12 by dendritic cells activated by TLR ligation is dependent on MyD88 signaling, whereas TRIF signaling is indispensable for TLR synergy. J Leukocyte Biol. 2010; 88(1):189-99. [PubMed: 20360404]

45. Randolph GJ, Angeli V, Swartz MA. Dendritic-cell trafficking to lymph nodes through lymphatic vessels. Nat Rev Immunol. 2005; 5(8):617-28. [PubMed: 16056255]

46. Kim S, Kim HO, Kim HJ, Lee K, Kim HS. Generation of functionally mature dendritic cells from elutriated monocytes using polyinosinic: polycytidylic acid and soluble CD40 ligand for clinical application. Clin Exp Immunol. 2008; 154(3):365-74. [PubMed: 18782327]

47. Homma Y, Cao S, Shi X, Ma X. The Th2 transcription factor c-Maf inhibits IL-12p35 gene expression in activated macrophages by targeting NF-kappaB nuclear translocation. J Interferon Cytokine Res. 2007; 27(9):799-808. [PubMed: 17892401]

48. Cohen S, Yoshioka T, Lucarelli M, Hwang LH, Langer R. Controlled delivery systems for proteins based on poly(lactic/glycolic acid) microspheres. Pharm Res. 1991; 8(6):713-720. [PubMed: 2062800]

49. Bala I, Hariharan S, Kumar MN. PLGA nanoparticles in drug delivery: the state of the art. Crit Rev Ther Drug Carrier Syst. 2004; 21(5):387-422. [PubMed: 15719481]

50. Choi JW, Park JH, Baek SY, Kim DD, Kim HC, Cho HJ. Doxorubicin-loaded poly(lactic-coglycolic acid) microspheres prepared using the solid-in-oil-in-water method for the transarterial chemoembolization of a liver tumor. Colloids Surf, B. 2015; 132:305-12.

51. Bell GM, Anderson AE, Diboll J, Reece R, Eltherington O, Harry RA, Fouweather T, MacDonald C, Chadwick T, McColl E, Dunn J, Dickinson AM, Hilkens CM, Isaacs JD. Autologous tolerogenic dendritic cells for rheumatoid and inflammatory arthritis. Ann Rheum Dis. 2017; : 76227.doi: 10.1136/annrheumdis-2015-208456

52. Harry RA, Anderson AE, Isaacs JD, Hilkens CM. Generation and characterisation of therapeutic tolerogenic dendritic cells for rheumatoid arthritis. Ann Rheum Dis. 2010; 69(11):2042-50. [PubMed: 20551157] 
53. Amoozgar Z, Wang L, Brandstoetter T, Wallis SS, Wilson EM, Goldberg MS. Dual-layer surface coating of PLGA-based nanoparticles provides slow-release drug delivery to achieve metronomic therapy in a paclitaxel-resistant murine ovarian cancer model. Biomacromolecules. 2014; 15(11): 4187-94. [PubMed: 25251833]

54. Chitkara D, Kumar N. BSA-PLGA-based core-shell nano-particles as carrier system for watersoluble drugs. Pharm Res. 2013; 30(9):2396-409. [PubMed: 23756758]

55. Klose D, Siepmann F, Elkharraz K, Siepmann J. PLGA-based drug delivery systems: importance of the type of drug and device geometry. Int J Pharm. 2008; 354(1-2):95-103. [PubMed: 18055140]

56. Sharp FA, Ruane D, Claass B, Creagh E, Harris J, Malyala P, Singh M, O’Hagan DT, Petrilli V, Tschopp J, O'Neill LA, Lavelle EC. Uptake of particulate vaccine adjuvants by dendritic cells activates the NALP3 inflammasome. Proc Natl Acad Sci U S A. 2009; 106(3):870-5. [PubMed: 19139407]

57. Errea A, Cayet D, Marchetti P, Tang C, Kluza J, Offermanns S, Sirard JC, Rumbo M. Lactate Inhibits the Pro-Inflammatory Response and Metabolic Reprogramming in Murine Macrophages in a GPR81-Independent Manner. PLoS One. 2016; 11(11):e0163694. [PubMed: 27846210]

58. Lerch MM, Conwell DL, Mayerle J. The anti-inflammasome effect of lactate and the lactate GPR81-receptor in pancreatic and liver inflammation. Gastroenterology. 2014; 146(7):1602-5. [PubMed: 24780214]

59. Romero-Garcia S, Moreno-Altamirano MM, Prado-Garcia H, Sanchez-Garcia FJ. Lactate Contribution to the Tumor Microenvironment: Mechanisms, Effects on Immune Cells and Therapeutic Relevance. Front Immunol. 2016; 7:52. [PubMed: 26909082]

60. Peter K, Rehli M, Singer K, Renner-Sattler K, Kreutz M. Lactic acid delays the inflammatory response of human monocytes. Biochem Biophys Res Commun. 2015; 457(3):412-8. [PubMed: 25582773]

61. Pacheco P, White D, Sulchek T. Effects of microparticle size and Fc density on macrophage phagocytosis. PLoS One. 2013; 8(4):e60989. [PubMed: 23630577]

62. Champion JA, Walker A, Mitragotri S. Role of particle size in phagocytosis of polymeric microspheres. Pharm Res. 2008; 25(8):1815-21. [PubMed: 18373181]

63. Garapaty A, Champion JA. Non-covalent phosphorylcholine coating reduces protein adsorption and phagocytic uptake of micro-particles. Chem Commun (Cambridge, U K). 2015; 51(72): 13814-7.

64. Mihret A, Mamo G, Tafesse M, Hailu A, Parida S. Dendritic Cells Activate and Mature after Infection with Mycobacterium tuberculosis. BMC Res Notes. 2011; 4:247. [PubMed: 21777464]

65. Tostanoski LH, Chiu YC, Gammon JM, Simon T, Andorko JI, Bromberg JS, Jewell CM. Reprogramming the Local Lymph Node Microenvironment Promotes Tolerance that Is Systemic and Antigen Specific. Cell Rep. 2016; 16(11):2940-2952. [PubMed: 27626664]

66. Hsieh CS, Macatonia SE, Tripp CS, Wolf SF, O’Garra A, Murphy KM. Development of TH1 CD4+ T cells through IL-12 produced by Listeria-induced macrophages. Science. 1993; 260(5107):547-9. [PubMed: 8097338]

67. Ceonzo K, Gaynor A, Shaffer L, Kojima K, Vacanti CA, Stahl GL. Polyglycolic acid-induced inflammation: role of hydrolysis and resulting complement activation. Tissue Eng. 2006; 12(2): 301-8. [PubMed: 16548688]

68. Ma JY, Jiang WW, Zhou ZT, Li JM, Wang HY. The promoting angiogenesis and anti-inflammation effect of scutellarin on polyglycolic acid scaffold of balb/c mice model. J Asian Nat Prod Res. 2008; 10(11-12):1147-53. [PubMed: 19031261]

69. Lewis JS, Zaveri TD, Crooks CP, Keselowsky BG. Microparticle surface modifications targeting dendritic cells for non-activating applications. Biomaterials. 2012; 33(29):7221-32. [PubMed: 22796161]

70. Yoshida M, Babensee JE. Poly(lactic-co-glycolic acid) enhances maturation of human monocytederived dendritic cells. J Biomed Mater Res. 2004; 71(1):45-54.

71. Alexis F. Factors affecting the degradation and drug-release mechanism of poly(lactic acid) and poly[(lactic acid)-co-(glycolic acid)]. Polym Int. 2005; 54(1):36-46. 
72. Kenley RA, Lee MO, Mahoney R, Sanders LM. Poly(lactic-co-glycolide) Decomposition Kinetics in Vivo and in Vitro. Macromolecules. 1987; 20:2398-2403.

73. Wang N, Wu XS. Synthesis, characterization, biodegradation, and drug delivery application of biodegradable lactic/glycolic acid oligomers: Part II. Biodegradation and drug delivery application. J Biomater Sci, Polym Ed. 1998; 9(1):75-87.

74. Acharya AP, Clare-Salzler MJ, Keselowsky BG. A high-throughput microparticle microarray platform for dendritic cell-targeting vaccines. Biomaterials. 2009; 30(25):4168-77. [PubMed: 19477505]

75. Richardson KE, Tolbert NE. Oxidation of glyoxylic acid to oxalic acid by glycolic acid oxidase. J Biol Chem. 1961; 236:1280-1284. [PubMed: 13741299]

76. Ikejima K, Iimuro Y, Forman DT, Thurman RG. A diet containing glycine improves survival in endotoxin shock in the rat. Am J Physiol. 1996; 271(1):G97-G103. [PubMed: 8760112]

77. De Saedeleer CJ, Copetti T, Porporato PE, Verrax J, Feron O, Sonveaux P. Lactate activates HIF-1 in oxidative but not in Warburg-phenotype human tumor cells. PLoS One. 2012; 7(10):e46571. [PubMed: 23082126]

78. Pearce EJ, Everts B. Dendritic cell metabolism. Nat Rev Immunol. 2015; 15(1):18-29. [PubMed: 25534620]

79. Xie H, Hanai J, Ren JG, Kats L, Burgess K, Bhargava P, Signoretti S, Billiard J, Duffy KJ, Grant A, Wang X, Lorkiewicz PK, Schatzman S, Bousamra M, Lane AN, Higashi RM, Fan TW, Pandolfi PP, Sukhatme VP, Seth P. Targeting lactate dehydrogenase-a inhibits tumorigenesis and tumor progression in mouse models of lung cancer and impacts tumor-initiating cells. Cell Metab. 2014; 19(5):795-809. [PubMed: 24726384]

80. Rajamaki K, Nordstrom T, Nurmi K, Akerman KE, Kovanen PT, Oorni K, Eklund KK. Extracellular acidosis is a novel danger signal alerting innate immunity via the NLRP3 inflammasome. J Biol Chem. 2013; 288(19):13410-9. [PubMed: 23530046]

81. Lawrence T. The nuclear factor NF-kappaB pathway in inflammation. Cold Spring Harbor Perspect Biol. 2009; 1(6):a001651.

82. Tornatore L, Thotakura AK, Bennett J, Moretti M, Franzoso G. The nuclear factor kappa B signaling pathway: integrating metabolism with inflammation. Trends Cell Biol. 2012; 22(11): 557-66. [PubMed: 22995730]

83. Oeckinghaus A, Ghosh S. The NF-kappaB family of transcription factors and its regulation. Cold Spring Harbor Perspect Biol. 2009; 1(4):a000034.

84. Sun SC. Non-canonical NF-kappaB signaling pathway. Cell Res. 2011; 21(1):71-85. [PubMed: 21173796]

85. Zou GM, Hu WY. LIGHT regulates CD86 expression on dendritic cells through NF-kappaB, but not JNK/AP-1 signal transduction pathway. J Cell Physiol. 2005; 205(3):437-43. [PubMed: 15895390]

86. Fong TC, Wu Y, Kipps TJ. Identification of a promoter element that regulates tissue-specific expression of the human CD80 (B7.1) gene. J Immunol. 1996; 157(10):4442-50. [PubMed: 8906820]

87. O’Sullivan B, Thompson A, Thomas R. NF-kappa B as a therapeutic target in autoimmune disease. Expert Opin Ther Targets. 2007; 11(2):111-22. [PubMed: 17227228] 

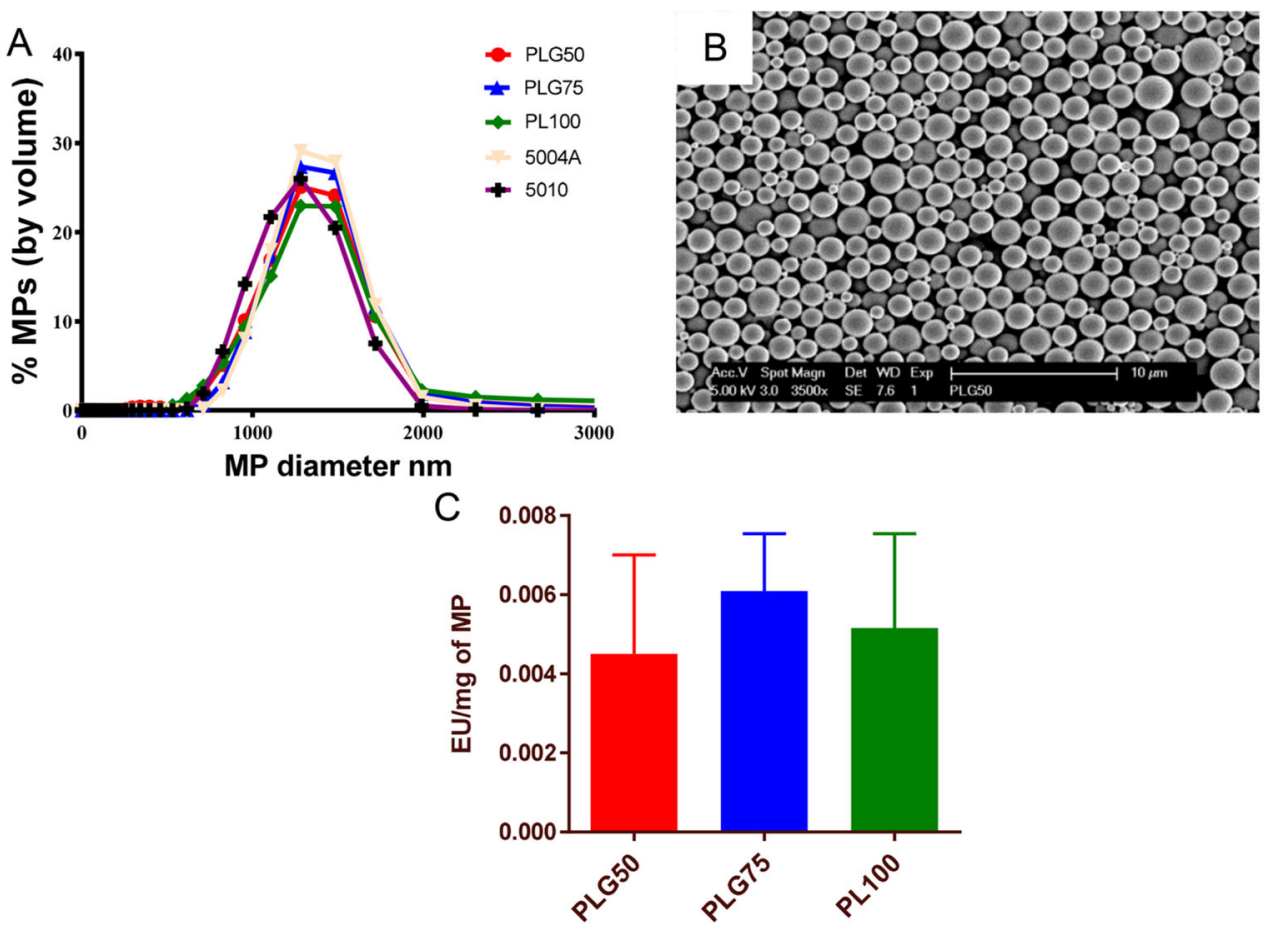

Figure 1.

Poly(D,L-lactic-co-glycolic) MP characterization. (A) Size distribution by volume of fabricated MPs using DLS. (B) Scanning electron microscopy image of the PLG50 formulation showing spherical nature and average size of about $1 \mu \mathrm{m}$. (C) Endotoxin levels per milligram of MP as assessed via the ChromoLAL assay; histogram bars represent mean and standard error. 

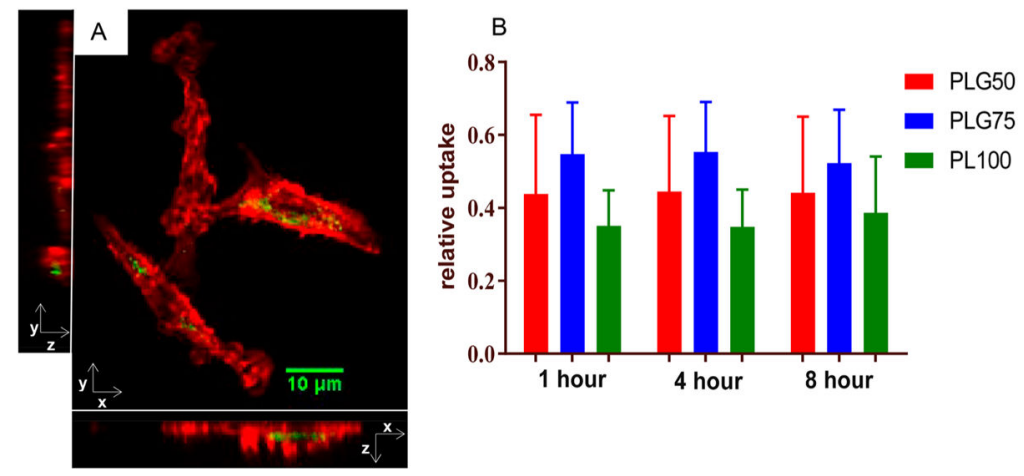

Figure 2.

Uptake of $1 \mu \mathrm{m}$ PLGA MPs. (A) Internalization of MPs by DCs is demonstrated using confocal microscopy. Adherent DCs were incubated with fluorescein (green)-loaded MPs for $1 \mathrm{~h}$ and subsequently washed with PBS to remove unphagocytosed MP. DCs were then fixed, permeabilized, and stained for actin cytoskeletal elements (red). The image shows the $X-Y, Y-Z$, and $X-Z$ optical sections, confirming engulfment of the MPs. (B) DiD-stained DCs were incubated with rhodamine 6G-loaded MPs and assessed for uptake between 1 and $8 \mathrm{~h}$. The relative uptake was calculated as the number of events double positive for DiD and rhodamine $6 \mathrm{G}$ divided by the total number of DiD-stained cells. No significant differences in uptake were observed between the different MP formulations at any time point $(n=3$ biological replicates). 

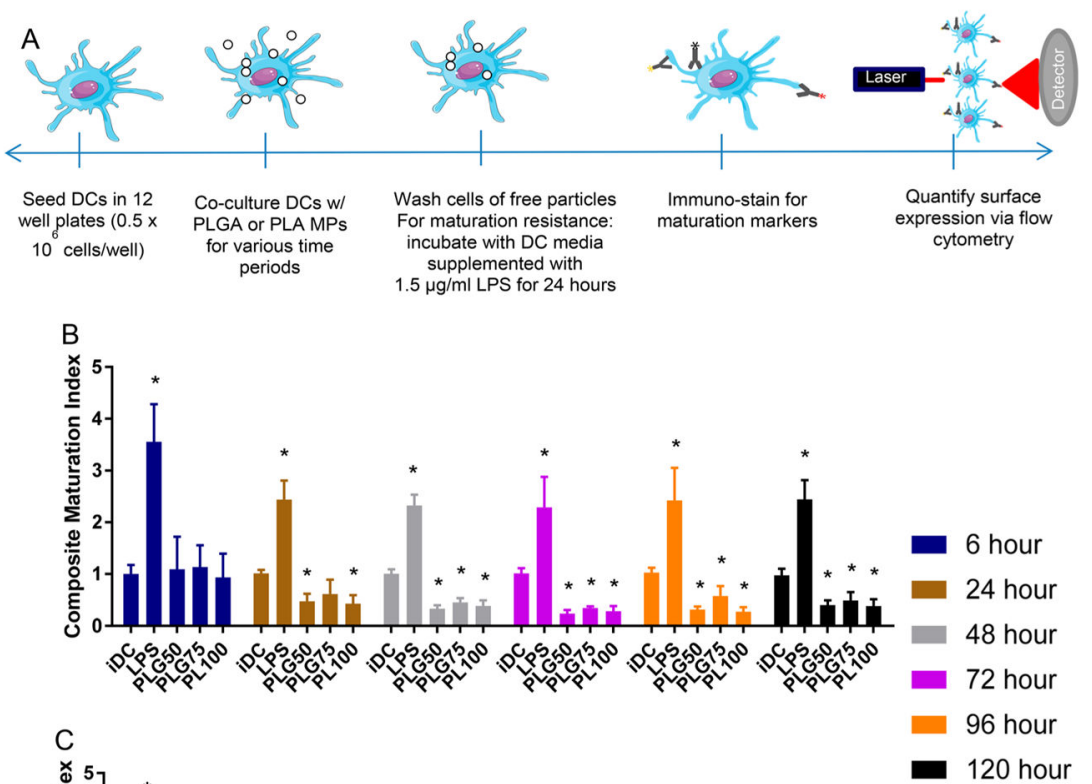

Figure 3 .

Low molecular weight PLGA MPs are immunosuppressive in coculture with DCs. (A) Schematic of the experimental setup used for the maturation and maturation resistance experiments. (B) Dendritic cells were incubated with 2 different formulations of PLGA (50:50 and 75:25) and PLA MPs at time points ranging from 6 to $120 \mathrm{~h}$, washed, and then subsequently immunostained for MHCII, CD80, and CD86. Immature DCs and LPS treated $(1.5 \mu \mathrm{g} / \mathrm{mL}) \mathrm{DCs}$ served as controls for nonactivated and activated groups, respectively. The composite maturation indices (unweighted average of the expression of CD80, CD86, and MHCII) of DCs at each time point are shown, normalized to the iDC population. (C) Dendritic cells treated with PLGA MPs and subsequently challenged with LPS show resistance to LPS maturation. DCs were incubated with 2 different formulations of PLGA (50:50 and 75:25) and PLA at time points ranging from 6 to $120 \mathrm{~h}$, washed, and then subsequently challenged with LPS $(1.5 \mu \mathrm{g} / \mathrm{mL})$ for $24 \mathrm{~h}$. Pair-wise significant differences from the iDC population are denoted by the $*$ symbol ( $\mathrm{p} \leq 0.05 ; \mathrm{n}=3$ biological replicates). 


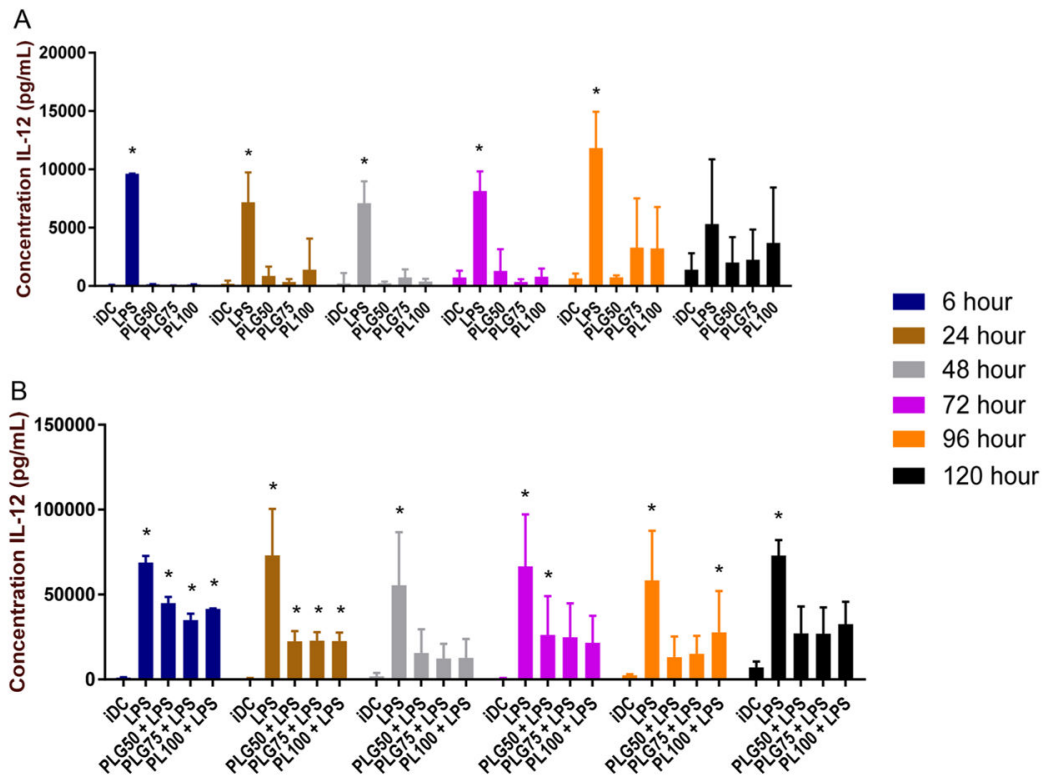

Figure 4.

Secretion of IL-12 is stymied when DCs are cocultured with low molecular weight PLGA/PLA MPs, particularly after LPS stimulation. (A) Supernatants were collected from DCs cocultured with PLGA or PLA, and IL-12 was quantified using an absorbance-based sandwich ELISA. The * symbol represents a pairwise comparison to the immature DC population ( $p \leq 0.05$ ). (B) Supernatants were collected from DCs cocultured with PLGA or PLA and then challenged with $1.5 \mu \mathrm{g} / \mathrm{mL}$ LPS. IL-12 was quantified using a sandwich ELISA. The * symbol represents a pairwise comparison to the immature DC population ( $p \leq$ $0.05)$. Data shown represent mean cytokine concentration \pm standard error $(n \geq 3$ biological replicates). 


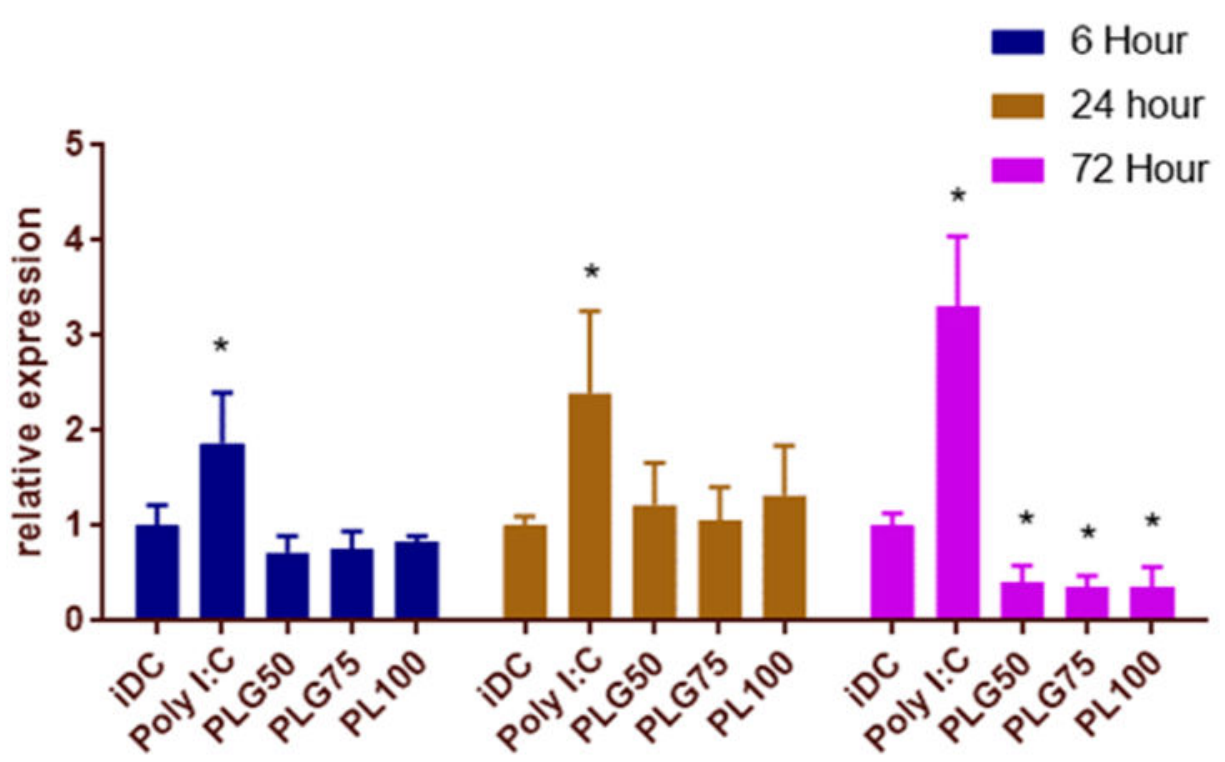

Figure 5.

Low molecular weight PLGA MPs downregulate the expression of CCR7 after $72 \mathrm{~h}$ of MP incubation. After coculture with PLGA MPs for 6, 24, and $72 \mathrm{~h}$, DCs were lifted and immunostained for CCR7. At $72 \mathrm{~h}$ of incubation, PLGA-treated DCs had significantly lowered expression of CCR7. The * symbol represents a pairwise comparison to the immature DC population ( $p \leq 0.05 ; n=3$ biological replicates for each group). 


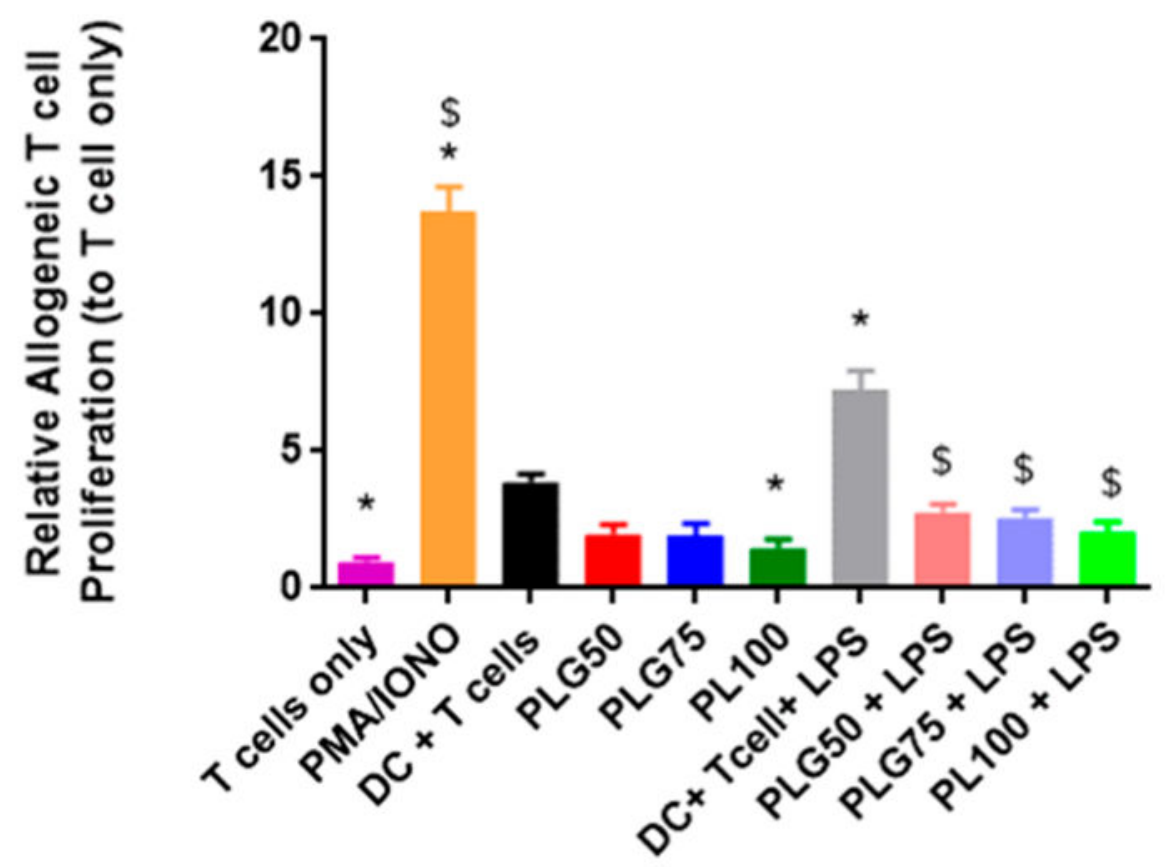

Figure 6.

PLGA MP uptake induces suppressive DCs, resulting in decreased allogeneic T cell proliferation downstream. Dendritic cells were pretreated with PLGA MPs for $48 \mathrm{~h}$ and then cocultured with allogenic CD4+ T cells for $72 \mathrm{~h}$ or challenged with LPS for $24 \mathrm{~h}$ then cocultured with allogenic CD4+ T cells for $72 \mathrm{~h}$. Allogenic T cell proliferation was measured via CFSE dye dilution. Controls in this experiment included a population of $\mathrm{T}$ cells only and T cells exposed to a stimulatory cocktail of PMA and IONO. The * symbol represents a pairwise comparison to the $\mathrm{DC}+\mathrm{T}$ cell group $(p \leq 0.05)$. The $\$$ symbol represents a pairwise comparison to the DC+ T cell+ LPS group $(p \leq 0.05)$. Data shown represent the mean \pm standard error ( $n=3$ biological replicates). 


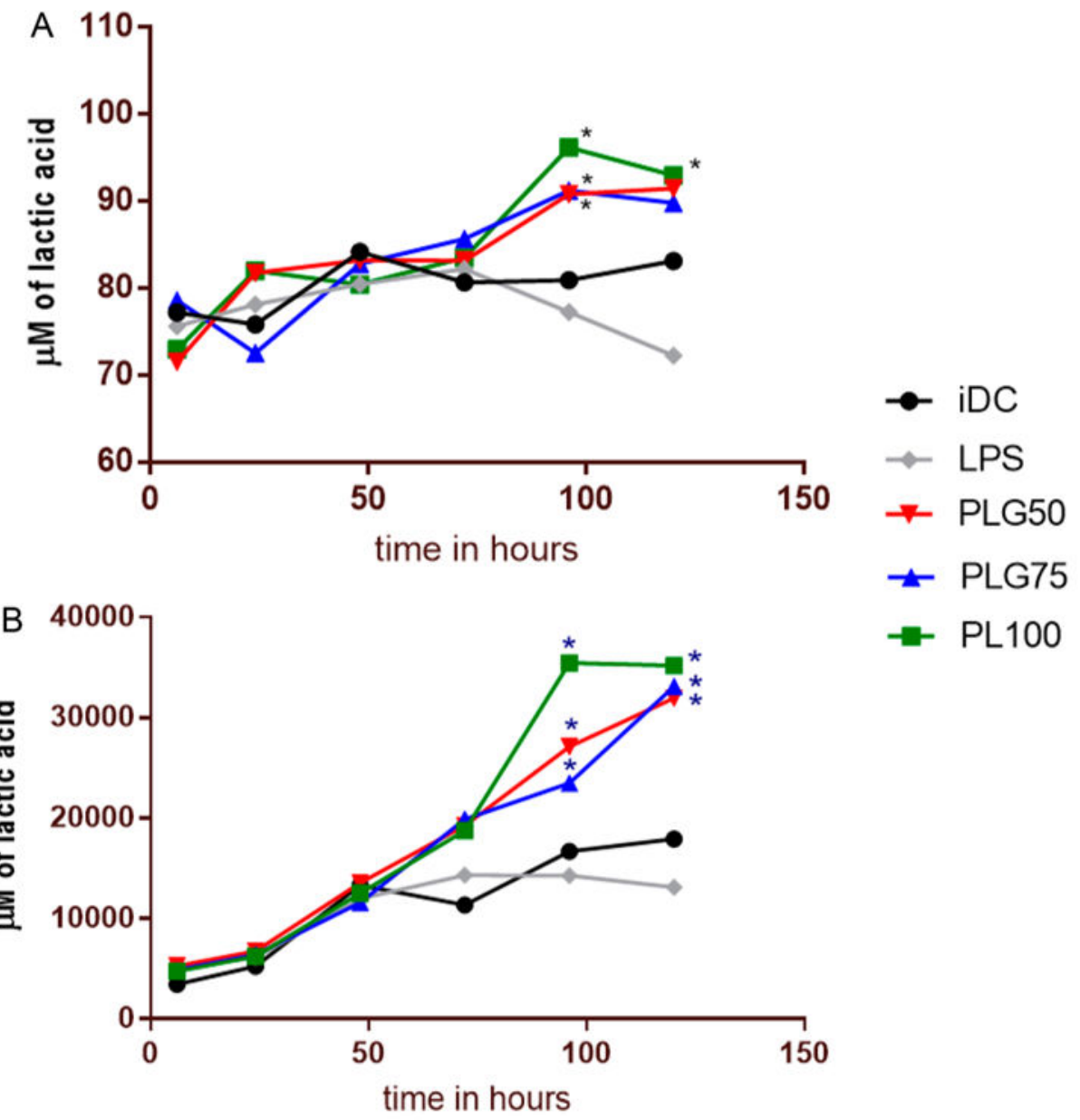

Figure 7.

Intracellular and extracellular concentrations of L-lactic acid increase with DC exposure to PLGA MPs. (A) The intracellular concentration of L-lactic acid in DCs after coculture with PLGA/PLA MPs was measured using an enzyme-based, colorimetric assay. The * symbol represents a pairwise significant difference in lactic acid concentration compared to that of iDCs ( $p<0.05 ; n=3$ biological replicates per formulation per time point). Significance was determined using a repeated measure two-way ANOVA followed by pairwise comparisons (posthoc Tukey test) between the mean of every treatment group. Error bars were omitted to aid in visual distinction between formulations. (B) The extracellular L-lactic acid in the supernatant of DCs cocultured with PLGA and PLA MPs was measured using an enzymebased colorimetric assay by collecting the supernatants at $6,24,48,72,96$, and $120 \mathrm{~h}$, pelleting any free particles by centrifugation at $\sim 10000 \mathrm{~g}$, and then using a lactic acid detection kit from Cayman Chemical. The * symbol represents a pairwise significance difference as compared to iDC $(p<0.05 ; n=3$ biological replicates per formulation per time point). Significance was determined using two-way ANOVA of the entire data set followed by comparisons of the means of each treatment group at each time point using a posthoc Tukey test. Error bars were omitted to aid in visual distinction between formulations. 


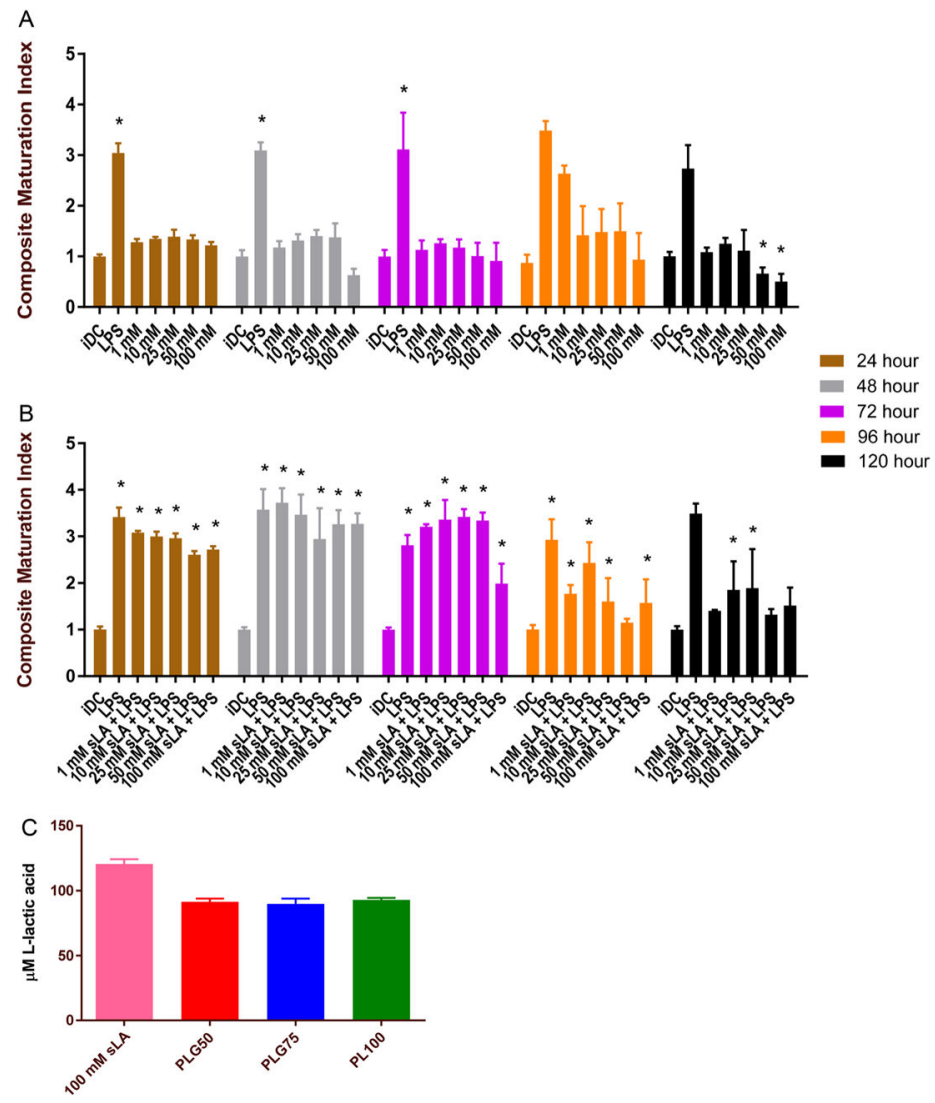

Figure 8.

Culturing DCs with sodium-L-lactate at high concentrations produces similar immunosuppressive effects to those observed when DCs are cocultured with low molecular weight PLGA/PLA MPs. (A) DCs were cultured with sLA at concentrations ranging from 1 to $100 \mathrm{mM}$. The composite maturation indexes (unweighted average of the expression of CD80, CD86, and MHCII) of DCs at each time point are shown, normalized to the iDC population. At higher concentrations of lactic acid, specifically $100 \mathrm{mM}$, the composite maturation index for DCs is significantly lower than that of the immature DC population, particularly at later time points. The * symbol represents a pairwise comparison to the immature DC population $(p \leq 0.05)$. (B) DCs were cultured with sodium-L-lactate at concentrations ranging from 1 to $100 \mathrm{mM}$ at the designated time points and then challenged with LPS for $24 \mathrm{~h}$. Similar to PLGA/PLA MPs, sLA provides resistance to maturation at higher concentrations. The * symbol represents a pairwise comparison to the iDC population $(p \leq 0.05)(\mathrm{C})$ The intracellular L-lactic acid concentration was measured after $120 \mathrm{~h}$ of incubation with $100 \mathrm{mM}$ lactic acid in the culture media. Interestingly, the concentration of intracellular L-lactic acid is similar to the concentration that accumulates after incubation with PLA and PLGA MPs after $120 \mathrm{~h}$. Data shown represent the mean \pm standard error $(n \geq$ 3 biological replicates). 


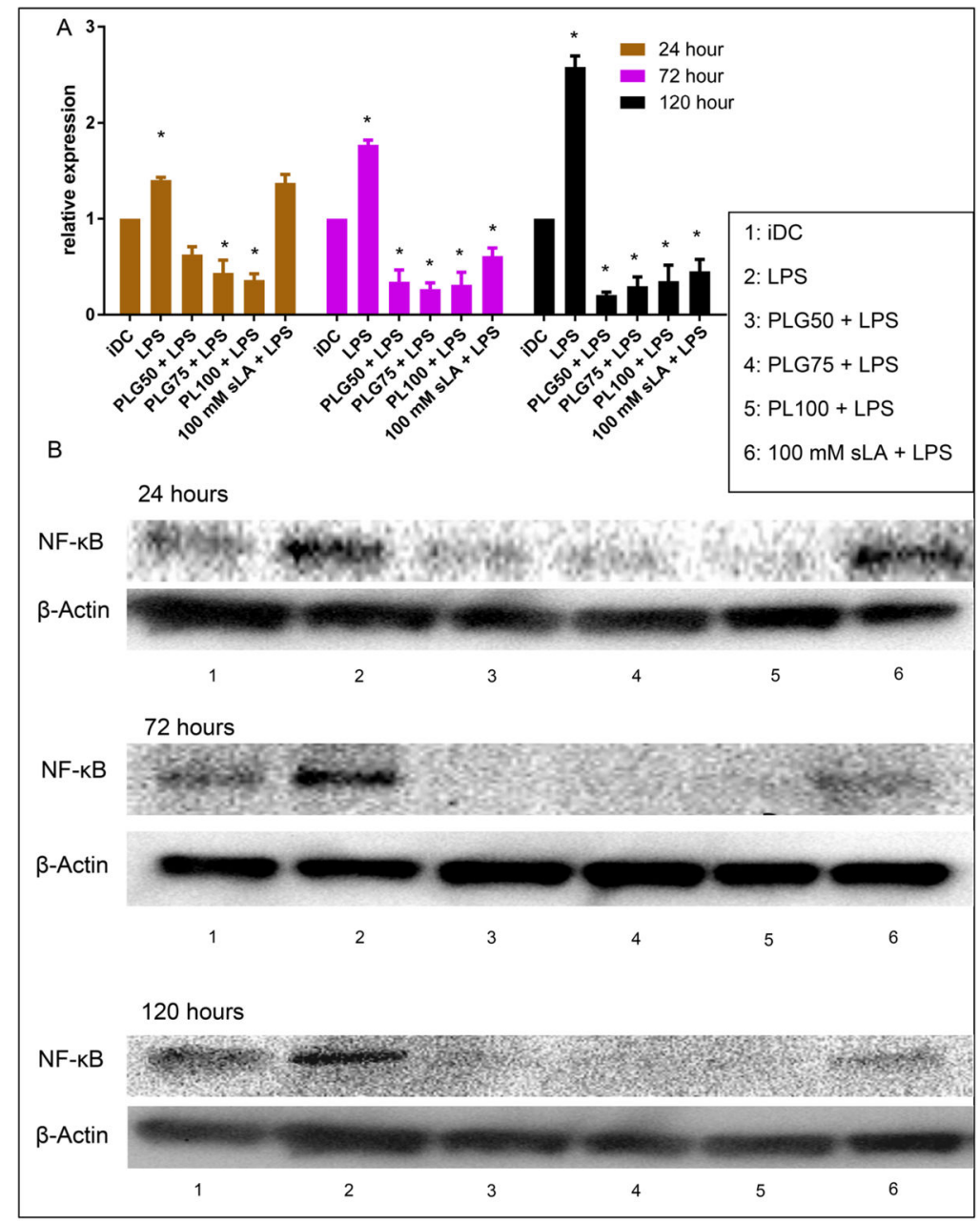

Figure 9.

Coculture with PLGA MPs drives downregulation of the inflammatory transcription factor NF- $\kappa$ B in LPS-stimulated DCs. (A) Dendritic cells $\left(1 \times 10^{6}\right)$ were incubated with 2 different formulations of PLGA MPs (50:50 and 75:25), PLA MPs, or $100 \mathrm{mM}$ sLA for 24,72, and $120 \mathrm{~h}$, washed, and then subsequently challenged with LPS $(1.5 \mu \mathrm{g} / \mathrm{mL})$ for $24 \mathrm{~h}$. Cell lysate was then extracted and separated via SDS PAGE. Protein was then transferred and subsequently stained for NF- $\kappa$ B. Relative expression represents the optical density (OD; determined using ImageJ) of the band at $65 \mathrm{kDa}$ for each treatment normalized to that for the iDC group. Pair-wise significant differences from the iDC population is denoted by the * symbol ( $p \leq 0.05 ; n \geq 3$ biological replicates). Data shown represent the mean and standard error. (B) Representative Western blotting bands as measured using chemiluminescence. The top band from each time point is the representative band at $65 \mathrm{kDa}$ correlating with the NF$\kappa \mathrm{B}$ expression. The bottom band from each time point represents the loading control at 42 $\mathrm{kDa}$ correlating with the expression of endogenous $\beta$-actin. 


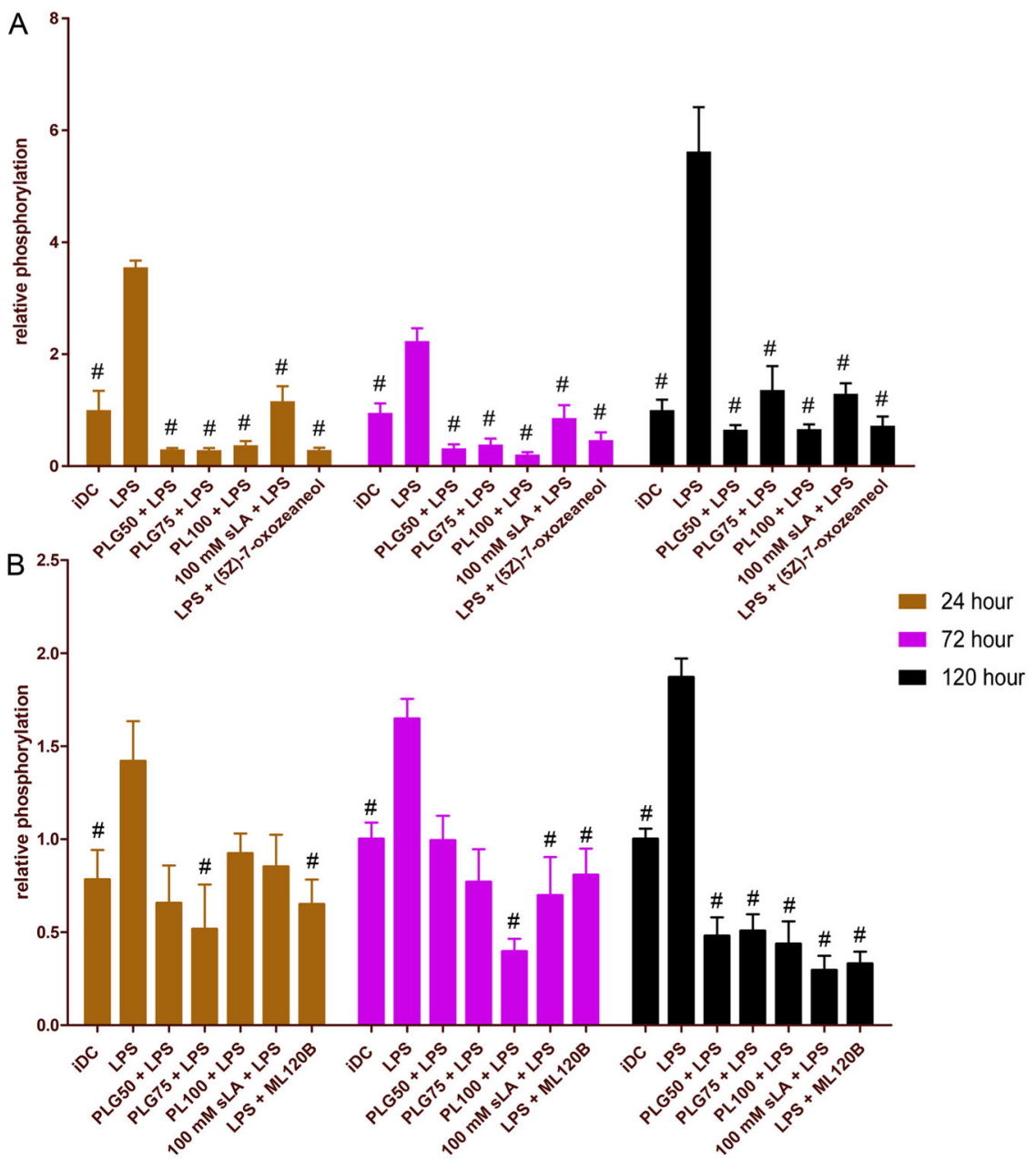

Figure 10.

Dendritic cell coculture with PLGA MPs decreases the phosphorylation of (A) TAK1 and (B) IKK $\beta$, two important intermediates in the canonical activation of NF- $\kappa$ B. Dendritic cells $(0.5 \times 106)$ were incubated with 2 different formulations of PLGA MPs (50:50, 75:25), PLA MPs, or $100 \mathrm{mM}$ sLA for 24,72 , and $120 \mathrm{~h}$, washed, and then subsequently challenged with LPS $(1.5 \mu \mathrm{g} / \mathrm{mL})$ for $24 \mathrm{~h}$. Cell were then fixed, permeabilized, and stained with antiphosphoTAK1 or anti-phosphoIKK $\beta$ antibodies and subsequently analyzed by flow cytometry. Relative phosphorylation represents the mean fluorescence intensity normalized to the iDC population. A pairwise significant difference from LPS-treated population is denoted by the \# symbol ( $p \leq 0.05 ; n \geq 3$ biological replicates). Data shown represent the mean and standard error. 


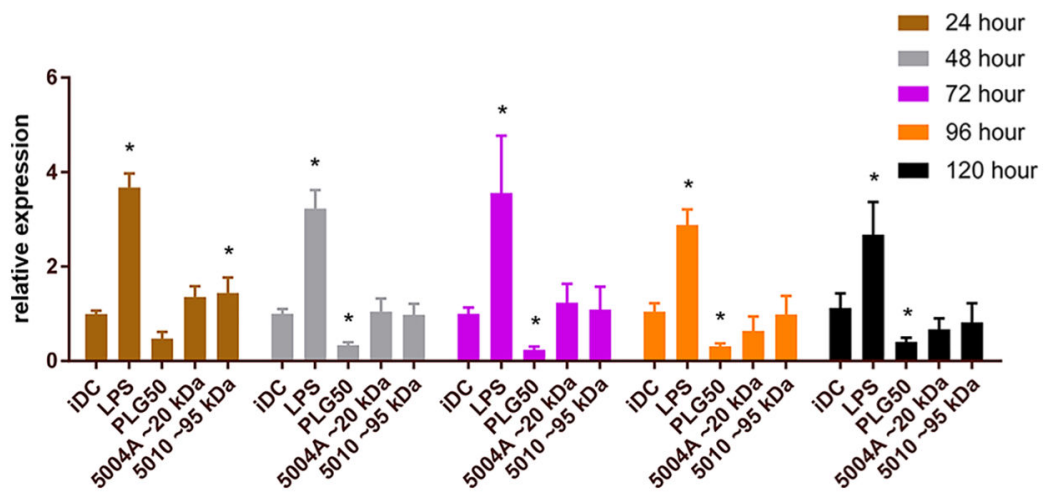

Figure 11.

Immunophenotypic changes in MP-treated DCs vary with the molecular weight of PLGA molecular weight. Briefly, DCs were cocultured with PLGA MPs of higher molecular weight (5004A and 5010) for time points ranging from 6 to $120 \mathrm{~h}$. The composite maturation indexes (unweighted average of the expression of CD80, CD86, and MHCII) of DCs at each time point are shown, normalized to the iDC population. The larger molecular weight polymers 5004A and 5010 do not provide immunosuppressive effects but rather maintain a CMI similar to that of immature dendritic cells. Immature DCs and LPSstimulated DCs $(1.5 \mu \mathrm{g} / \mathrm{mL})$ serve as negative and positive controls, respectively. PLG50treated cells serve as a reference to prior experiments. Pair-wise significant differences from the iDC population are denoted by the ${ }^{*} \operatorname{symbol}(p \leq 0.05 ; n=3$ biological replicates). Data shown represent the mean \pm standard error. 


\section{Table 1}

$\zeta$-Potential of Differently Fabricated PLGA/PLA Microparticles

particle formulation $\quad \zeta$-potential $(\mathrm{mV})$

PLG50 $-27.45 \pm 1.1$

PLG75 $-32.3 \pm 0.75$

PL100 $-42.1 \pm 0.32$

$5004 \mathrm{~A} \quad-26.68 \pm 1.2$

$5010-19.32 \pm 0.89$ 